Open Access

\title{
Targeted Recombinant Progeny: a design for ultra-high resolution mapping of Quantitative Trait Loci in crosses between inbred or pure lines
}

Eliyahu M Heifetz ${ }^{1 *}$ and Morris Soller ${ }^{2}$

\begin{abstract}
Background: High-resolution mapping of the loci (QTN) responsible for genetic variation in quantitative traits is essential for positional cloning of candidate genes, and for effective marker assisted selection. The confidence interval (QTL) flanking the point estimate of QTN-location is proportional to the number of individuals in the mapping population carrying chromosomes recombinant in the given interval. Consequently, many designs for high resolution QTN mapping are based on increasing the proportion of recombinants in the mapping population. The "Targeted Recombinant Progeny" (TRP) design is a new design for high resolution mapping of a target QTN in crosses between pure, or inbred lines. It is a three-generation procedure generating a large number of recombinant individuals within a QTL previously shown to contain a QTN. This is achieved by having individuals that carry chromosomes recombinant across the target QTL interval as parents of a large mapping population; most of whom will therefore carry recombinant chromosomes targeted to the given QTL. The TRP design is particularly useful for high resolution mapping of QTN that differentiate inbred or pure lines, and hence are not amenable to high resolution mapping by genome-wide association tests.

Results: In the absence of residual polygenic variation, population sizes required for achieving given mapping resolution by the TRP- $F_{2}$ design relative to a standard $F_{2}$ design ranged from 0.289 for a QTN with standardized allele substitution effect $=0.2$, mapped to an initial QTL of 0.2 Morgan to 0.041 for equivalent QTN mapped to an initial QTL of $0.02 \mathrm{M}$. In the presence of residual polygenic variation, the relative effectiveness of the TRP design ranges from 1.068 to 0.151 for the same initial QTL intervals and QTN effect. Thus even in the presence of polygenic variation, the TRP can still provide major savings. Simulation showed that mapping by TRP should be based on 30-50 markers spanning the initial interval; and on at least 50 or more $G_{2}$ families representing this number of recombination points,
\end{abstract}

Conclusions: The TRP design can be an effective procedure for achieving high and ultra-high mapping resolution of a target QTN previously mapped to a known confidence interval (QTL).

Keywords: QTN, QTL, High resolution mapping, Inbred lines, F2 mapping design, Polygenic variation

\footnotetext{
*Correspondence: eliyahu100@gmail.com

'JCT - Lev Academic Center, 21 Havaad Haleumi, Jerusalem, Israel

Full list of author information is available at the end of the article
} 


\section{Background}

Genetic analysis of complex quantitative traits involves mapping the polymorphic sites (QTN - Quantitative Trait Nucleotide) responsible for genetic variation in these traits to their individual chromosomal regions (QTL - Quantitative Trait Loci). The QTL is defined here as a confidence interval $(\mathrm{CI})$ within which the QTN is located with confidence $(1-\alpha)$, where $\alpha$ is the probability that the QTN is found outside the CI. High resolution QTL mapping (i.e., localizing the QTL to a narrow confidence interval) is essential for positional cloning of candidate genes, and for effective marker assisted selection or marker assisted introgression. With the advent of high density SNP microarrays, high resolution mapping of segregating QTN within populations of outcrossing species (all animals, and many plants), is now based on marker-QTN association due to population-wide linkage disequilibrium (LD), so-called "Whole Genome Association Studies" (WGAS) [1]. WGAS exploits for mapping the very large number of recombination events accumulated across an outcrossing population over the untold generations of sexual reproduction since the origin of the QTN. These recombination events limit population-wide LD between markers and QTN in the population to a very narrow region about the QTN, so that statistically significant association between marker and QTN indicates that the QTN is very close to the marker. Within pure lines of selfing species, or inbred lines of outcrossing species, however, markers and QTN are at fixation. Hence, WGAS is clearly not possible and other designs have been developed. Many of these were already reviewed in the classic Darvasi paper [2]. Basically they fall into two types: Group I, designs that increase mapping resolution across the entire genome; Group II, designs that are targeted to a specific QTL. Group I designs include the Advanced Intercross Line (AIL) design [3,4] which can be applied ad hoc to any $\mathrm{F}_{2}$ population. These designs also include specialized mouse stocks based on the AIL principle, developed specifically for high resolution mapping, the Heterogeneous Stock (HS) [5] and the Diversity Outcross [6]. In a happy stroke of good fortune, the commercially available MF1 outbred stock, was adventitiously found to be highly suitable for Group I mapping $[7,8]$. All three stocks have the advantage that mapping is on the basis of founder haplotypes instead of single markers, in this way avoiding dilution of effects when the same marker allele is associated with both alternative QTN alleles. On the other hand they all have the limitation that they can only access QTN that are segregating among the founder lines of the crosses. Resources comparable to the HS, Diversity outcross and MF1 are not available for plant species. In the Near Isogenic Line (NIL) design, analyzed in detail in [9], the entire genome of a target donor line is dissected into smaller segments, each isolated in a different NIL through successive backcrossing to a recipient line followed by a number of selfing generations. Each segment can then be tested against the corresponding donor segment for QTL detection. Construction of NIL libraries was pioneered by the tomato geneticists $[10,11]$ and has since been applied with success in a wide assortment of plant species (listed in [9]). Also in Group I are new major resources consisting of sets of many Recombinant Inbred Lines (RIL) derived from intercrosses among a large set of founder parent lines chosen to maximize genetic diversity within the resource. These include the Collaborative Cross (CC) Mouse Resource population [12,13]; and the conceptually identical Multi-parent Advanced Generation Inter-Cross (MAGIC) resources in plants [14]. The MAGIC resource was first proposed by Cavanough [14], based on the discussions leading to the CC resource, and has already been applied to develop MAGIC populations in Arabidopsis [15], wheat [16] and rice [17]. The advantages and strengths of the CC and MAGIC resources are too many to detail here. When a large mapping population can be generated and genotyped but the limiting factor is phenotyping (as in microarray experiments), selective phenotyping (reviewed in [18]) can be employed to select a subset of individuals to maximize their mapping power, e.g., by maximizing their genotypic dissimilarity [19] or the complementariness of crossover sites within the sample [20].

Group II designs are aimed at high resolution mapping targeted to a specific QTL previously mapped with high power to a relatively large CI by standard $\mathrm{F}_{2}, \mathrm{BC}$, or AIL QTL-mapping designs. Group II designs were reviewed by Darvasi [2], and new designs do not seem to have been proposed since then. All of these designs are based on the principle of "Chromosome Dissection" pioneered by the Drosophila geneticists over half a century ago (e.g., [21]). In Recombinant Progeny Testing (RPT) [2, 22] a series of individuals in the original $F_{2}$ or $B C$ mapping population that carry recombinant chromosomes with the points of recombination laddered across the target region are queried individually as to whether the QTN location is upstream or downstream of the recombination point. In the Interval-Specific Congenic Strains (ISCS) design [23] the same class of individuals as for RPT are individually backcrossed repeatedly to one of the parental strains (chosen to be recessive for the QTL effect, if applicable) to retain only a segment containing the recombination point and small flanking donor intervals. This establishes a series of congenic strains that cover the target region. These are then queried individually to determine whether the QTN is located upstream or downstream of the recombination point. A great advantage of the ICSC design is the reduction in residual genetic variance by the repeated backcrossing to the 
inbred parent. This enables strain status with respect to the QTL to be determined with relatively few individuals. This design has been widely applied in mice (e.g., [24]). When large numbers of individuals are available for the mapping population, selective recombinant genotyping [25] can be employed to reduce genotyping costs.

In the present study, we propose a new, "Targeted Recombinant Progeny" (TRP) design for high and ultrahigh resolution mapping of specific target QTN that are at fixation within populations, but differ across populations, e.g., in crosses between pure lines of selfer species, or between highly inbred lines. The TRP design is a three-generation procedure for generating a large number of recombinant individuals within a QTL shown by previous mapping to contain a QTN. Similar to RPT and ISCS this is achieved by identifying "founder" individuals in an $\mathrm{F}_{2}, \mathrm{BC}$, or AIL population that carry chromosomes that are recombinant in the target QTL. In contrast to RPT, there is no attempt to determine QTN status of individual founders. Rather, by having these founder individuals serve as parents of a large progeny population, a mapping population is generated most of whose members carry recombinant chromosomes targeted to the given QTL. Since the TRP mapping population consists primarily of recombinant individuals, this provides for high resolution mapping of the QTN within its QTL, with appreciably smaller total mapping populations than required for equal precision by classical $\mathrm{F}_{2}, \mathrm{BC}$ or even AIL designs. The only condition is that the number of founder individuals is sufficient to provide enough points of recombination to refine the QTN location to the desired degree. It should be stressed, that the TRP design is aimed at high resolution mapping of a specific QTN previously mapped to a QTL. This contrasts to the classical $\mathrm{F}_{2}$, BC and AIL designs for which a single set of progeny provides the required recombinants for mapping all QTN that are segregating in the mapping population.

\section{Methods}

(i) Notation and assumptions

\section{Notation}

To simplify derivations, map distance are given in units of Morgans $(M)$, rather than centiMorgans (cM). Thus, $20 \mathrm{cM}=0.2 \mathrm{M}$.

\section{Assumptions}

We assume a QTN that has been previously mapped to a point location within a QTL of width $\mathrm{C} M$, with confidence level $(1-\alpha)$. The purpose of the TRP is to generate a new mapping population which is densely populated by recombinant chromosomes targeted to this QTL, so that a new point location with $(1-\alpha) \mathrm{CI}$ of width $\mathrm{c}=\mathrm{C} / \mathrm{s}$ is obtained, where $\mathrm{s}$ is the factor by which the original $\mathrm{CI}$ is reduced. The TRP achieves this by generating an
$\mathrm{F}_{2}$, BC or AIL population and identifying within it individuals that carry a recombinant chromosome in the target interval. These are then selfed or backcrossed to one of the parental lines to generate a TRP mapping population highly enriched with recombinant chromosomes in the interval of interest.

It is convenient to describe the TRP by starting with an $F_{1}$ generation created by crossing two pure lines homozygous for alternative alleles at a large number of marker loci and at the target QTL. However, the TRP can equally be initiated from any population (denoted the $G_{1}$ generation), with a similar $F_{1}$-type genetic structure. On the basis of previous mapping studies, these $G_{1}$ individuals will have genotypes of known haplotype composition, including phase of the QTN allele. By appropriate notation of marker and QTN alleles, these genotypes can be given the form: $M_{U}-Q^{-}-M_{D} / m_{U}-q--m_{D}$, where $M_{U}$ and $M_{D}$ are markers defining the upstream $\left(\mathrm{M}_{\mathrm{U}}\right)$ and downstream $\left(\mathrm{M}_{\mathrm{D}}\right)(1-\alpha) \mathrm{CI}$ boundaries of the original QTL of width $\mathrm{C}$ $\mathrm{M}$ (see Figure 1). Q and $\mathrm{q}$ are alternative alleles at the

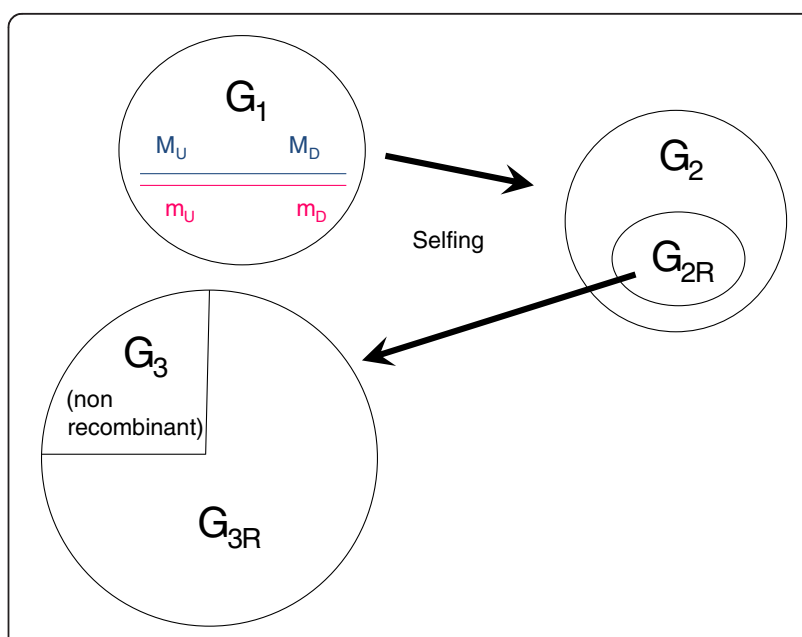

Figure 1 Construction of a TRP mapping population. We assume a QTN mapped to a known confidence interval bounded by markers $M_{\cup}$ and $M_{D}$. Construction of the TRP mapping population begins with one or more $G_{1}$ individuals heterozygous for alternative alleles at the QTN and for a large series of markers spanning the interval from $M_{\cup}$ to $M_{D}$. The $G_{1}$ individuals are selfed, generating a $G_{2}$ population. The $G_{2}$ population is genotyped for the markers $M_{U}$ and $M_{D}$ identifying a subset of individuals (the $G_{2 R}$ population) that carry a recombinant chromosome in this region together with one of the parental haplotypes. The $G_{2 R}$ individuals are genotyped for the full set of internal markers, identifying the point of recombination of their recombinant chromosome. They are selfed in turn to generate the $G_{3}$ population. The $G_{3}$ individuals are genotyped for one of the markers heterozygous in their $G_{2 R}$ parent to identify the haplotypes transmitted by the $G_{2 R}$ parent. $G_{3}$ individuals carrying one or two recombinant haplotypes (75\% of the total) form the $G_{3 R}$ mapping population. Non-recombinant $G_{3}$ individuals that carry only parental type haplotypes serve to correct for polygenic family effects 
QTN, and a large number of markers with alternative alleles (not shown) are found spanning the region between $\mathrm{M}_{\mathrm{U}}$ and $\mathrm{M}_{\mathrm{D}}$.

We now describe the construction of the TRP mapping population in detail. Based on Weller and Soller [26], we then derive the required size of the TRP mapping population to achieve target $(1-\alpha) \mathrm{CI}$ about the QTN point location and compare to that required by standard $\mathrm{F}_{2}, \mathrm{BC}$ or AIL mapping populations for equivalent precision.

\section{(ii) The $G_{2}$ population and the $G_{2 R}$ individuals}

Depending on the reproductive biology of the species, the $G_{1}$ parent individuals are selfed (TRP- $F_{2}$ design) or backcrossed to one of the parental lines (TRP-BC design) to produce a $G_{2}$ progeny population some of whom carry a recombinant chromosome in the target QTL. In what follows, we continue with the analysis of the TRP- $\mathrm{F}_{2}$ design. The TRP-BC design is a simpler application of the same principles and will be briefly described in Appendix I.

The $G_{2}$ progeny are genotyped for the markers $M_{U}$ and $M_{D}$, and $G_{2 R}$ individuals, each carrying a single recombinant chromosome in the interval $M_{U}$ to $M_{D}$, are identified (see Figure 1). In principle, this would also uncover triple recombinants but these will be in vanishingly small frequency and can safely be ignored. Since there are two types of recombinant haplotypes $\left(\mathrm{M}_{\mathrm{U}^{---}}\right.$ $\mathrm{m}_{\mathrm{D}}$, and $\mathrm{m}_{\mathrm{U}^{---}} \mathrm{M}_{\mathrm{D}}$ ) and two types of parental haplotypes $\left(M_{U^{---}} M_{D}\right.$, and $\left.m_{U^{--}-m_{D}}\right)$ there will be four types of $G_{2 R}$ individuals, as shown in Table 1 . In addition, a small proportion $\left(=C^{2}\right)$ of $G_{2 R}$ individuals carrying two independent recombinant chromosomes will also be produced. In practice, these individuals would not be included in the $G_{2 R}$ group, as the families they produce do not contain non-recombinant progeny needed to correct for polygenic family effects (see section $\mathrm{xv}$ for

Table 1 Composition of the entire $G_{3}$ population ${ }^{1}$

\begin{tabular}{|c|c|c|c|c|}
\hline $\mathbf{G}_{3}$ Class & $\mathrm{G}_{2 \mathrm{R}}$ parent & & & \\
\hline & $M_{\cup} m_{D} / M_{\cup} M_{D}$ & $M_{\cup} m_{D} / m_{\cup} m_{D}$ & $m_{\cup} M_{D} / M_{\cup} M_{D}$ & $m_{\cup} M_{D} / m_{\cup} m_{D}$ \\
\hline \multirow[t]{2}{*}{ Class I } & $M_{\cup} m_{D} / M_{\cup} m_{D}$ & $M_{U} m_{D} / M_{U} m_{D}$ & $m_{\cup} M_{D} / m_{\cup} M_{D}$ & $m_{\cup} M_{D} / m \cup M_{D}$ \\
\hline & $1 / 16 \mathrm{~d} A$ & $1 / 16 \mathrm{~d} B$ & $1 / 16-d C$ & $1 / 16-d D$ \\
\hline \multirow[t]{2}{*}{ Class II } & $M_{\cup} m_{D} / M_{U} M_{D}$ & $M_{\cup} m_{D} / m_{\cup} m_{D}$ & $m_{U} M_{D} / M_{U} M_{D}$ & $m_{\cup} M_{D} / m_{\cup} m_{D}$ \\
\hline & $2 / 16 \mathrm{~d} E$ & 2/16 h F & $2 / 16 h \mathrm{G}$ & 2/16-d H \\
\hline \multirow[t]{2}{*}{ Class III } & $M_{\cup} M_{D} / M_{\cup} M_{D}$ & $m_{\cup} m_{D} / m_{\cup} m_{D}$ & $M_{\cup} M_{D} / M_{\cup} M_{D}$ & $m_{U} m_{D} / m_{U} m_{D}$ \\
\hline & $1 / 16 \mathrm{~d}$ NR & $1 / 16-d$ NR & $1 / 16 \mathrm{~d} N \mathrm{NR}$ & $1 / 16-d$ NR \\
\hline
\end{tabular}

${ }^{1}$ Each cell represents a $G_{3}$ progeny group according to Class and the $G_{2 R}$ parent, showing: marker genotype of the progeny group (above); proportion of the progeny group in the total $\mathrm{G} 3$ population (below-left); genotypic value of the progeny group (below-center); code designation ( $A$ to $F$ ) of the progeny group (below-right). Class I, homozygous recombinant progeny; Class II, heterozygous recombinant progeny; Class III, homozygous non-recombinant progeny; $N R$, non-recombinant progeny group not included in the $G_{3 R}$ mapping population further details). To make up for this, it will be sufficient to increase the size of the $G_{2}$ population by the proportion $\mathrm{C}^{2}$, e.g., by $4 \%$ if the original $\mathrm{CI}$ is $0.20 \mathrm{M}$. This will be considered as negligible and will not be taken into account in what follows.

The $G_{2 R}$ individuals are genotyped for the markers spanning the region between $\mathrm{M}_{\mathrm{U}}$ and $\mathrm{M}_{\mathrm{D}}$, identifying the haplotype of the recombinant chromosome and the point of recombination. This information will allow some selection among the $G_{2 R}$ individuals chosen to produce the $G_{3}$ generation to obtain a more evenly spaced distribution of recombination points across the original QTL. It also enables the complete genotypes of the $G_{3}$ generation to be inferred from their $G_{2 R}$ parents, without requiring further genotyping of the $\mathrm{G}_{3}$ individuals (this is explained in the next section).

\section{(iii) Producing the $\mathrm{G}_{3 \mathrm{R}}$ mapping population and identifying a new point location for the QTN}

Continuing with the TRP- $F_{2}$ design, each parent $G_{2 R}$ individual will produce on selfing three classes of $G_{3}$ progeny: Class I, Double recombinants in proportion 0.25, carrying two recombinant haplotypes; Class II, Single recombinants in proportion 0.50 , carrying one recombinant and one non-recombinant (parental) haplotype; and Class III, Double non-recombinants in proportion 0.25 , carrying two non-recombinant parental haplotypes (Table 1). The three $G_{3}$ genotype classes within each family are identified by genotyping the $\mathrm{G}_{3}$ population for the pair of flanking markers $\left(M_{U}\right.$ and $\left.M_{D}\right)$ that define the target region. The combined Class I and Class II recombinant progeny of all $G_{2 R}$ individuals form the $G_{3 R}$ mapping population. Thus, in contrast to the usual $\mathrm{F}_{2}, \mathrm{BC}$ or even AIL designs, in which the mapping population consists of only a small proportion of informative recombinant progeny for any target QTL, the TRP mapping population consists primarily of informative recombinant progeny, targeted to a specific QTL. The nonrecombinant Class III $G_{3}$ progeny group is not included in the $G_{3 R}$ mapping population. However, as will be shown later (section $\mathrm{xv}$ ), it will contribute to evaluation and correction of family polygenic values.

Once $G_{3 R}$ recombinant status is determined, further genotyping is not required to obtain full $G_{3 R}$ genotypes, since (neglecting rare new recombination), the full genotype of any $\mathrm{G}_{3 \mathrm{R}}$ individual across the small target c interval, is determined by the genotype of the $G_{2 R}$ parent of that individual.

At some point along the way, either before or after genotyping, the $G_{3}$ or $G_{3 R}$ population is phenotyped. A suitable t-test (or other appropriate test) is implemented in the $G_{3 R}$ population for each marker in the interval $M_{U}$ to $M_{D}$, with data pooled across all $G_{3 R}$ families. The marker with the most significant $t$-test is identified as 
the new point location of the QTN, denoted $\mathrm{M}_{1}$. Our goal is to determine the total $\mathrm{G}_{3}$ population size, $\mathrm{N}_{\mathrm{TG} 3}$, required to have the $(1-\alpha) \mathrm{CI}$ about $\mathrm{M}_{1}$ equal to $\mathrm{c}=\mathrm{C} / \mathrm{s}$. We do this in two steps. basing our approach on Weller and Soller [26]. As shown in that paper, for any given mapping population, the (1- $\alpha)$ confidence level of a symmetrical interval of width $\mathrm{c} M$, about the point location of a QTN is solely a function of: (i) $\alpha$, (ii) the number, $K$, of recombinant chromosomes across that interval in the mapping population, and (iii) the standardized allele substitution effect, $d$, at the QTN. It follows, that for given $\alpha$ and $\mathrm{d}, \mathrm{K}$ is a constant. Consequently, the required size, $\mathrm{N}_{\mathrm{G} 3}$, of a mapping population to deliver a (1- $\left.\alpha\right)$ CI of width $\mathrm{c}$ will be the size of the population that will deliver $\mathrm{K}$ recombinant chromosomes across an interval of size $\mathrm{c}$. In the first step, then, we calculate $\mathrm{K}$ for the given $\mathrm{d}$ and target $\alpha . N_{G 3}$ will then depend solely on the proportion, $R$, of recombinant chromosomes in the mapping population such that, $N_{G 3}=K / R$. In the second step, we note that since the new point location of the QTN in the original QTL is not known, the entire original $(1-\alpha) C I=C M$, is considered as composed of s consecutive smaller sub-CI each of width $\mathrm{c} M$. Each of these s sub-CI will require generating a $\mathrm{G}_{3}$ population of size $\mathrm{N}_{\mathrm{G} 3}$. Thus, $\mathrm{N}_{\mathrm{TG} 3}$, the total number of $\mathrm{G}_{3}$ progeny required to map the QTL to the sub-CI of width c, within its original QTL will be:

$$
\mathrm{N}_{\mathrm{TG} 3}=\mathrm{sN}_{\mathrm{G} 3}
$$

We now derive expressions for $\mathrm{N}_{\mathrm{G} 3}$, as a function of $\alpha$ and $\mathrm{d}$ for the TRP- $\mathrm{F}_{2}$-design.

\section{(iv) Required size of the $G_{3}$ mapping population for given $a$ and $d$}

At this point it is convenient to shift our attention from Table 1, which gives the overall composition of the $G_{3}$ population; to Table 2 which focuses our attention on the new point location of the QTN at $\mathrm{M}_{1}$, and its boundary marker, $M_{2}$. With respect to these markers, the $G_{3}$ population derived from the $\mathrm{G}_{2 \mathrm{R}}$ parents has the composition shown in Table 2. All told there are four $G_{2 R}$ family types and eight $G_{3 R}$ recombinant progeny groups, denoted A to $H$. For each $G_{3 R}$ recombinant group, Table 2 also shows the genotypic value, and the expected frequency in that fraction of the $\mathrm{G}_{3}$ population defining the new $95 \%$ $\mathrm{CI}=\mathrm{c}$ about $\mathrm{M}_{1}$, calculated on the assumption that each of the four $G_{2 R}$ parental types contributes equally to the $\mathrm{G}_{3}$ population.

Given the $\mathrm{G}_{3 \mathrm{R}}$ mapping population, with single markermapping the new point location of the QTN will be at the marker, $M_{1}$, with the greatest difference between alternative marker genotypes, with marker $\mathrm{M}_{2}$ defining the one-side limit of the target $(\mathbf{1}-\boldsymbol{\alpha}) \mathrm{CI}$. As shown by Weller and Soller [26] the probability that the CI of
Table 2 Composition of the fraction of the $G_{3}$ population centered on the new QTN point location $\left(M_{1}\right)$, and its boundary marker $\left(M_{2}\right)^{1}$

\begin{tabular}{lllll}
\hline G Class & $\mathbf{G}_{2 \mathbf{R}}$ parent & & & \\
\hline \multirow{4}{*}{ Class I } & $M_{1} m_{2} / M_{1} M_{2}$ & $M_{1} m_{2} / m_{1} m_{2}$ & $m_{1} M_{2} / M_{1} M_{2}$ & $m_{1} M_{2} / m_{1} m_{2}$ \\
& $M_{1} m_{2} / M_{1} m_{2}$ & $M_{1} m_{2} / M_{1} m_{2}$ & $m_{1} M_{2} / m_{1} M_{2}$ & $m_{1} M_{2} / m_{1} M_{2}$ \\
& $1 / 16 d A$ & $1 / 16 d B$ & $1 / 16-d C$ & $1 / 16-d D$ \\
Class II & $M_{1} m_{2} / M_{1} M_{2}$ & $M_{1} m_{2} / m_{1} m_{2}$ & $m_{1} M_{2} / M_{1} M_{2}$ & $m_{1} M_{2} / m_{1} m_{2}$ \\
& $2 / 16 d E$ & $2 / 16 h F$ & $2 / 16 h G$ & $2 / 16-d H$ \\
Class III & $M_{1} M_{2} / M_{1} M_{2}$ & $m_{1} m_{2} / m_{1} m_{2}$ & $M_{1} M_{2} / M_{1} M_{2}$ & $m_{1} m_{2} / m_{1} m_{2}$ \\
& $1 / 16 d ~ N R$ & $1 / 16-d ~ N R$ & $1 / 16 d ~ N R$ & $1 / 16-d N R$
\end{tabular}

${ }^{1}$ Each cell shows a $G_{3}$ progeny group according to Class and the $G_{2 R}$ parent, showing: marker genotype of the progeny group (above); proportion of the progeny group in the $G_{3 R}$ population (below-left); genotypic value of the progeny group (below-center); code designation ( $A$ to $F$ ) of the progeny group (below-right). Class I, homozygous recombinant progeny; Class II, heterozygous recombinant progeny; Class III, homozygous non-recombinant progeny; NR, non-recombinant progeny group not included in the $G_{3}$ mapping population.

QTL location includes the marker $\mathrm{M}_{2}$ located at a remove of $L M$ from $M_{1}$, is equal to the probability of obtaining the value

$$
Z_{\alpha / 2}=\mathrm{D} / \mathrm{SE}(\mathrm{D})
$$

where,

$\mathrm{Z}_{\alpha / 2}$ is the standard normal variable corresponding to a probability of $\alpha / 2, D=E\left(M_{1}\right)-E\left(M_{2}\right)$, where $E\left(M_{1}\right)$ is the expected effect at $M_{1}$ (QTN located at the marker), $E\left(M_{2}\right)$ is the expected QTN effect at $M_{2}$ (located at a remove from the QTN) considering recombinant individuals only; and $\mathrm{SE}(\mathrm{D})$ is the standard error of D. Some thought will show that only recombinant individuals in the region $M_{1}$ to $M_{2}$ can contribute to a difference in expectation for $M_{1}$ and $M_{2}$, as non-recombinants have the same value at both markers.

Letting italics denote the mean genotypic value of the corresponding marker genotype group (including recombinant genotypes only), we have

$$
\begin{array}{r}
\mathrm{E}\left(\mathrm{M}_{1}\right)=M_{1} M_{1}-m_{1} m_{1}, \mathrm{E}\left(\mathrm{M}_{2}\right)=M_{2} M_{2}-m_{2} m_{2}, \\
\mathrm{D}=\left(M_{1} M_{1}-m_{1} m_{1}\right)-\left(M_{2} M_{2}-m_{2} m_{2}\right)
\end{array}
$$

From Table 2 it is apparent that each of the four marker genotype groups is composed of three recombinant marker groups. For example the marker genotype group $\mathrm{M}_{2} \mathrm{M}_{2}$ is composed of recombinant genotype groups $C, D$, and $G$ of Table 2 with respective genotypes: $m_{1} M_{2} / m_{1} M_{2}$, $m_{1} M_{2} / m_{1} M_{2}$, and $m_{1} M_{2} / M_{1} M_{2}$; having genotypic values $-d$, $-d$, and $h$; frequencies $1 / 16,1 / 16$, and $2 / 16$ of the $G_{3}$ population; and relative frequencies $1 / 4,1 / 4$, and $1 / 2$ within the $\mathrm{M}_{2} \mathrm{M}_{2}$ genotype. The mean genotypic value of the $\mathrm{M}_{2} \mathrm{M}_{2}$ genotype group, including recombinants only $\left(M_{2} M_{2}\right)$ is the mean of the genotype groups $\mathrm{C}, \mathrm{D}$, and $\mathrm{G}$, 
weighted by their relative frequencies in the $\mathrm{M}_{2} \mathrm{M}_{2}$ recombinant group, i.e. $1 / 4,1 / 4$ and $1 / 2$, respectively.

On this basis, letting $A, B, C, D, E, F, G, H$, represent the genotypic values of the corresponding genotype groups, we have

$$
\begin{aligned}
& \mathrm{M}_{1} \mathrm{M}_{1}=(A / 4)+(B / 4)+(E / 2) \\
& \mathrm{m}_{1} \mathrm{~m}_{1}=(C / 4)+(D / 4)+(H / 2) \\
& \mathrm{M}_{2} \mathrm{M}_{2}=(C / 4)+(D / 4)+(G / 2) \\
& \mathrm{m}_{2} \mathrm{~m}_{2}=(A / 4)+(B / 4)+(F / 2)
\end{aligned}
$$

Substituting in (1) and combining like terms, we obtain

$$
\mathrm{D}=(1 / 2)(A+B-C-D+E+F-G-H)
$$

Substituting genotypic values of the recombinant groups we have

$$
D=(1 / 2)(d+d+d+d+d+h-h+d)=3 d
$$

To calculate $\mathrm{SE}(\mathrm{D})$, we assume that variance within the $G_{3}$ families is the same as variance within the $F_{2}$ generation (set to 1.0 for standardization). This is conservative, as the variance within $G_{3}$ families will generally be less than in an $F_{2}$ population, depending on degree of homzoygosity in their $G_{2 R}$ parent. On this basis, we can write:

$$
\sigma_{\mathrm{A}}^{2}=\sigma_{\mathrm{B}}^{2}=\sigma_{\mathrm{C}}^{2}=\sigma_{\mathrm{D}}^{2}=1 /\left(N_{G 3} / 16\right)=16 / N_{G 3} \quad(\text { as each of }
$$
these genotype groups comprises $1 / 16$ of the $G_{3}$ mapping population of size $\mathrm{N}_{\mathrm{G} 3}$

$\sigma_{\mathrm{E}}^{2}=\sigma_{\mathrm{F}}^{2}=\sigma_{\mathrm{G}}^{2}=\sigma_{\mathrm{H}}^{2}=1 /\left(N_{G 3} / 8\right)=8 / N_{G 3}$ (as each of these genotype groups comprises $1 / 8$ of the entire $G_{3}$ mapping population).

Then,

$$
\begin{aligned}
\mathrm{SE}^{2}(\mathrm{D}) & =(1 / 4)\left[\left(4\left(16 / \mathrm{N}_{\mathrm{G} 3}\right)+4\left(8 / \mathrm{N}_{\mathrm{G} 3}\right)\right]\right. \\
& =\left(16 / \mathrm{N}_{\mathrm{G} 3}+8 / \mathrm{N}_{\mathrm{G} 3}\right)=24 / \mathrm{N}_{\mathrm{G} 3}
\end{aligned}
$$

Substituting, we have

$$
\mathrm{Z}_{\alpha / 2}=3 \mathrm{~d} /\left(24 / \mathrm{N}_{\mathrm{G} 3}\right)^{0.5}
$$

Solving for $\mathrm{N}_{\mathrm{G} 3}$, we have

$$
\mathrm{N}_{\mathrm{G} 3}=24 \mathrm{Z}_{\alpha / 2}{ }^{2} / 9 \mathrm{~d}^{2}=2.67 \mathrm{Z}_{\alpha / 2}{ }^{2} / \mathrm{d}^{2}
$$

For example, if we set $\alpha=0.05$ and $d=0.2$, we have $\mathrm{Z}_{\alpha / 2}=1.96$, and $\mathrm{N}_{\mathrm{G} 3}=256.4$

Note, however, that the interval between $M_{1}$ and $M_{2}$ defines only half of the CI of QTL location. Hence, to cover the entire $\mathrm{CI}$ would require twice this

$$
\mathrm{N}_{\mathrm{G} 3}=5.34 \mathrm{Z}_{\alpha / 2}{ }^{2} / \mathrm{d}^{2}
$$

On these assumed values for $\alpha$ and $d$, the total $G_{3 R}$ population required for $\mathrm{CI}(0.95)=\mathrm{N}_{\mathrm{G} 3}=512.85$ This number is constant for given $d$, and $\alpha$, and does not depend on the target size of the confidence interval e.g., for $\alpha=0.05$ and $\mathrm{d}=0.25, \mathrm{~N}_{\mathrm{G} 3}=328.22$. If $\mathrm{N}_{\mathrm{G} 3}$ is achieved across a small interval, then the (1- $\alpha) \mathrm{CI}$ will be narrow; and if $\mathrm{N}_{\mathrm{G} 3}$ is achieved across a large interval, than the $(1-\alpha)$ CI will be wide.

Note, that in contrast to the usual $\mathrm{F}_{2}$ or similar mapping populations where the difference between alternative marker genotype groups is a function of proportion of recombination between marker and QTL, this is not the case for the TRP design, for which, since it is based on recombinant progeny only, the difference between alternative marker genotype groups is independent of proportion of recombination.

(v) Required total $\mathrm{G}_{3}$ population size, $\mathrm{N}_{\mathrm{TG}}$

Since the location of the QTN in the original QTL is not known, the entire original $\mathrm{CI}_{(1-\alpha)}=\mathrm{C} \mathrm{M}$, is considered as composed of $\mathrm{s}$ consecutive smaller sub-CI $\mathrm{I}_{(1-\alpha)}$, each of width $\mathrm{c} M$ (the target $\mathrm{CI}_{(1-\alpha)}$ ). Each of these $\mathrm{s}$ subintervals will require generating a $G_{3}$ population of size $\mathrm{N}_{\mathrm{G} 3}$. Thus, for the example above $(\alpha=0.05, \mathrm{~d}=0.2)$ the total number of $G_{3}$ progeny required to map the QTL to the sub-CI of size $\mathrm{c}=\mathrm{C} / \mathrm{s}$ within its original QTLR will be :

$$
\mathrm{N}_{\mathrm{TG} 3}=\mathrm{sN}_{\mathrm{G} 3}=\mathrm{s} 512.85
$$

As noted, this number is constant for given s, d, and $\alpha$, and does not depend on the target size c. Continuing with the same example $(\alpha=0.05, d=0.20)$, if we are reducing an original $\mathrm{CI}$ of $\mathrm{C}=0.20 \mathrm{M}$ to a target $\mathrm{CI}$ of $0.10 \mathrm{M}(\mathrm{s}=2)$, then $\mathrm{N}_{\mathrm{G} 3}=512.85$, and $\mathrm{N}_{\mathrm{TG} 3}=2 * 512.85=$ 1025.70 Of this total, $75 \%$ are included in the actual $\mathrm{G}_{3 \mathrm{R}}$ mapping population, and $25 \%$ are produced but are nonrecombinant and not included in the mapping population.

\section{(vi) Required number of $G_{2 R}$ parent individuals}

The number of $G_{2 R}$ individuals needed to produce the required number of $\mathrm{G}_{3}$ progeny for each sub-CI of size $c$, is:

$$
\mathrm{N}_{\mathrm{G} 2 \mathrm{R}}=\mathrm{N}_{\mathrm{G} 3} / \mathrm{n}
$$

where

$\mathrm{n}$ is the number of progeny that are produced by selfing each $G_{2 R}$ parent.

Continuing our example, and assuming $\mathrm{n}=50, \mathrm{~N}_{\mathrm{G} 2 \mathrm{R}}=$ $512.85 / 50=10.26$. It is important that $\mathrm{N}_{\mathrm{G} 2 \mathrm{R}}$ is large enough to provide a sufficient density of recombination points across the target QTL to define the sub-CI boundaries with a degree of precision (see simulation for further details). 


\section{(vii) Required $G_{2}$ population size}

By definition, when $c$ is small the proportion of $G_{1}$ gametes carrying a recombinant chromosome across the interval c $M$, will be c. In the $G_{2}$ generation produced from these gametes, a proportion $\mathrm{C}^{2}$ will carry two recombinant chromosomes and are excluded from the $G_{3 R}$ mapping population as explained above. As $C^{2}$ is generally small it is conveniently neglected in the calculations. In the remaining $G_{3 R}$ population, all recombinants across the region $\mathrm{c}$, will be present in proportion $2 \mathrm{c}(1-\mathrm{c})$, as heterozygotes carrying a recombinant chromosome together with a parental haplotype. Thus, as a close approximation, a bit on the high side, we have

$\mathrm{N}_{\mathrm{G} 2 \mathrm{R}}=2 \mathrm{c}(1-\mathrm{c}) \mathrm{N}_{\mathrm{G} 2}$ and solving for $\mathrm{N}_{\mathrm{G} 2}$ we have

$$
\mathrm{N}_{\mathrm{G} 2}=\mathrm{N}_{\mathrm{G} 2 \mathrm{R}} / 2 \mathrm{c}(1-\mathrm{c})
$$

Noting that $\mathrm{N}_{\mathrm{G} 2 \mathrm{R}}=\mathrm{N}_{\mathrm{G} 3} / \mathrm{n}$ and $\mathrm{N}_{\mathrm{G} 2}=\mathrm{N}_{\mathrm{G} 2 \mathrm{R}} / 2 \mathrm{c}(1-\mathrm{c})$, we can solve for $\mathrm{N}_{\mathrm{G} 2}$ as a function of $\mathrm{N}_{\mathrm{G} 3}$

$$
\mathrm{N}_{\mathrm{G} 2}=\mathrm{N}_{\mathrm{G} 3} / 2 \mathrm{nc}(1-\mathrm{c})
$$

This is convenient as $\mathrm{N}_{\mathrm{G} 3}$ is the basic number determining all the remaining numbers.

The same total of $G_{2}$ individuals needed to yield $N_{G 2 R}$ recombinant individuals for one sub-CI of size c $\mathrm{M}$, simultaneously produces $\mathrm{N}_{\mathrm{G} 2 \mathrm{R}}$ recombinant individuals for each sub-CI of size c $\mathrm{M}$ across the entire genome. Hence, the same $\mathrm{G}_{2}$ population of size $\mathrm{N}_{\mathrm{G} 2}$ can provide $\mathrm{N}_{\mathrm{G} 2 \mathrm{R}}$ individuals for all sub-CI of the designated QTL (and indeed, as noted previously, for any other QTL mapped in the original $\mathrm{F}_{2}$ population).

Thus, for our example, $\mathrm{C}=0.2, \mathrm{c}=0.1, \mathrm{n}=50, \mathrm{~N}_{\mathrm{G} 3}=$ 512.75 , so that

$$
\mathrm{N}_{\mathrm{G} 2}=512.85 / 2 * 0.1 * 0.90 * 50=56.98
$$

That is, a $G_{2}$ population of size 56.98 individuals (113.97 chromosomes), will contain $10.26 \mathrm{G}_{2 \mathrm{R}}$ recombinants for each target interval of $0.1 \mathrm{M}$ in an initial CI of size $0.2 \mathrm{M}$.

\section{(viii) Required $G_{1}$ population size}

The number of $G_{1}$ individuals required to produce the $G_{2}$ population will obviously equal

$$
\mathrm{N}_{\mathrm{G} 1}=\mathrm{N}_{\mathrm{G} 2} / \mathrm{n}=\mathrm{N}_{\mathrm{G} 3} /(2 \mathrm{nc}(1-\mathrm{c})) / \mathrm{n}=\mathrm{N}_{\mathrm{G} 3} / 2 \mathrm{n}^{2} \mathrm{c}(1-\mathrm{c})
$$

For our example, $\mathrm{N}_{\mathrm{G} 1}=512.85 / 450=1.14$, so that 2 or $3 \mathrm{G}_{1}$ individuals should suffice.

(ix) Total progeny required across the $G_{1}, G_{2}$ and $G_{3}$ generations $\left(\mathrm{N}_{\mathrm{TRP}}\right)$

Combining expressions for $\mathrm{N}_{\mathrm{G} 1}, \mathrm{~N}_{\mathrm{G} 2}$ and $\mathrm{N}_{\mathrm{TG} 3}$, as function of $\mathrm{N}_{\mathrm{G} 3}$, we have

$$
\begin{aligned}
& N_{T R P}=N_{G 3} / 2 n^{2} c(1-c)+N_{G 3} / 2 n c(1-c)+\mathrm{sN}_{\mathrm{G} 3} \\
& =N_{\mathrm{G} 3}\left(1 / 2 n^{2} \mathrm{c}(1-\mathrm{c})+1 / 2 \mathrm{nc}(1-\mathrm{c})+\mathrm{s}\right)
\end{aligned}
$$

For our example, $\mathrm{N}_{\mathrm{G} 3}=512.85, \mathrm{n}=50, \mathrm{c}=0.1, \mathrm{~s}=2$

$$
\mathrm{N}_{\mathrm{TRP}}=1093.91
$$

The contribution of $\mathrm{N}_{\mathrm{G} 1}$ is always negligible, and can safely be ignored. For the present example with relatively large $\mathrm{c}$, the contribution of $\mathrm{N}_{\mathrm{G} 2}$ is small, but when $\mathrm{c}$ is small, this is not the case, and $\mathrm{N}_{\mathrm{G} 2}$ makes an appreciable contribution to $\mathrm{N}_{\text {TRP. }}$.

To reduce the same $20 \mathrm{cM}$ original QTL to $2 \mathrm{cM}(\mathrm{s}=$ 10), would require $5,196.71$ individuals. All the increase will come from the increased $G_{3}$ population; $G_{1}$ and $G_{2}$ remain the same.

\section{(x) Total required genotyping and phenotyping}

All individuals of the $G_{2}$ generation are genotyped for the pair of markers flanking the original QTL to identify the $G_{2 R}$ individuals. These, making up $2 c(1-c)$ of the $G_{2}$ generation, are genotyped for $\mathrm{k}$ internal markers to locate the QTN more precisely within the original QTL. Based on the simulation results, about $\mathrm{k}=30$ to 50 internal markers should be genotyped in the $G_{2 R}$ individuals to extract maximum mapping information from a given $G_{3}$ population. Finally, the entire $G_{3}$ population is genotyped for a single marker, to identify their genotype (Class I, Class II or Class III in Tables 1 and 2) with respect to the haplotype transmitted from their $G_{2 R}$ parent. Thus, total genotyping data points (g.d.p.) will be

Total g.d.p. $=2 \mathrm{~N}_{\mathrm{G} 2}+2 \mathrm{c}(1-\mathrm{c}) \mathrm{kN}_{\mathrm{G} 2}+\mathrm{N}_{\mathrm{TG} 3}$

For example, from the combination $\mathrm{C}=0.02, \mathrm{~s}=4, \mathrm{c}=$ 0.005 we have $\mathrm{N}_{\mathrm{TG} 3}=7,591, \mathrm{~N}_{\mathrm{G} 2}=3,814$. Then, taking $\mathrm{k}$ $=50$, we have Total g.d.p. $=15,131$ : a remarkably low figure considering today's genotyping capacities and costs.

With respect to phenotyping, the entire $G_{3}$ population is phenotyped, but there is no need to phenotype the $G_{2}$ generation. If phenotyping costs are a major consideration, some form of selective phenotyping $[18,19]$ may be useful to reduce phenotyping data points at the expense of an increase in total population size and a negligible increase in genotyping costs

(xi) Total progeny required for an $\mathrm{F}_{2}$ mapping population to achieve equivalent map resolution:

Following Weller and Soller [26], population size required by an $\mathrm{F}_{2}$ population to achieve $95 \% \mathrm{CI}=\mathrm{c} \mathrm{M}$ is:

$$
\mathrm{N}_{\mathrm{F} 2}=15 / \mathrm{d}^{2} \mathrm{C}
$$

For our example, $\mathrm{d}=0.2, \mathrm{c}=0.1$ we have 


$$
\mathrm{N}_{\mathrm{F} 2}=3750
$$

Noting that in our example $\mathrm{N}_{\mathrm{G} 3}=5.34\left(\mathrm{Z}_{\mathrm{\alpha} / 2}^{2}\right) / \mathrm{d}^{2}$, the ratio of $\mathrm{N}_{\mathrm{TRP}}$ to $\mathrm{N}_{\mathrm{F} 2}$ is given by

$$
\begin{aligned}
& \left.\mathrm{N}_{\mathrm{TRP}} / \mathrm{N}_{\mathrm{F} 2}=5.34\left(1.96^{2}\right) / \mathrm{d}^{2}\right)(1 / 2 \mathrm{nc}(1-\mathrm{c})+\mathrm{s}) / \mathrm{N}_{\mathrm{F} 2} \\
& =\left(20.5 / \mathrm{d}^{2}\right)(1 / 2 \mathrm{nc}(1-\mathrm{c})+\mathrm{s}) / 15 /\left(\mathrm{d}^{2} \mathrm{c}\right) \\
& =20.5(1 / 2 \mathrm{nc}(1-\mathrm{c})+\mathrm{s}) / 15 / \mathrm{c} \\
& =43.27 / 150=0.288 \text { for } \mathrm{c}=0.1, \text { and } 0.0288 \text { for } \mathrm{c} \\
& =0.01
\end{aligned}
$$

Examination of the final expression for $\mathrm{N}_{\mathrm{TRP}} / \mathrm{N}_{\mathrm{F} 2}$ shows that it is a function of $\mathrm{n}, \mathrm{c}$, and s only, and is not affected by $\alpha$, nor, even more remarkably, by $\mathrm{d}$.

\section{(xii) Genotyping and phenotyping the $F_{2}$}

All $\mathrm{N}_{\mathrm{F} 2}$ individuals of the $\mathrm{F}_{2}$ mapping population are genotyped for the two markers flanking the original QTL of width $\mathrm{C}$. This will identify $2 \mathrm{C}(1-\mathrm{C}) \mathrm{F}_{2 \mathrm{R}}$ individuals carrying a recombinant chromosome in the target region. These are then genotyped for all $\mathrm{k}$ internal markers. Thus, Total g.d.p. $=2 \mathrm{~N}_{\mathrm{F} 2}+2 \mathrm{C}(1-\mathrm{C}) \mathrm{kN}_{\mathrm{F} 2}$. For the example we used for the TRP design $(C=0.02, s=4, c=0.005)$, we have $\mathrm{N}_{\mathrm{F} 2}=75,000$, giving Total g.d.p. $=297,000 ; 20$-fold more than required by the TRP design.

Ordinarily, all $\mathrm{N}_{\mathrm{F} 2}$ individuals would be phenotyped. However, if genotyping precedes phenotyping there is opportunity to greatly reduce phenotyping numbers by phenotyping the recombinant $\mathrm{F}_{2}$ individuals only. Similarly, if phenotyping precedes genotyping it may be possible to reduce genotyping numbers by use of selective genotyping [27] or even selective DNA pooling [28,29].

\section{(xiii) Mapping requirements in other TRP designs}

Mapping requirements in an TRP-AIL are the same as in an TRP- $\mathrm{F}_{2}$, except that the mapping population sizes are less by a factor of $0.5 \mathrm{t}$, where $\mathrm{t}$ is the generation number of the AIL. Mapping population size requirements in a TRP-BC depend strongly on degree of dominance at the QTL $(\mathrm{h})$, and range from twice to half that of an TRP- $F_{2}$, depending on whether $\mathrm{h}=0$ or $\mathrm{h}=1$, respectively. For the case $\mathrm{h}=0$, we expect the TRP-BC to require about twice as many data points as a TRP-F2 for equivalent power, and this is indeed what is found (Appendix I).

\section{(xiv) Polygenic variance component of SE(D)}

To this point we have calculated SE(D) on the assumption that the expected value of the $G_{3}$ marker genotype group within families is $\mu+\mathrm{d}, \mu-\mathrm{d}$ or $\mu+\mathrm{h}$, depending on the genotype at the QTL. The underlying assumption being that $\mu$ is the same for all families and marker groups within families. This is true for a standard $F_{2}$ population, where all $F_{1}$ parent individuals have the same polygenic value.

However, in the TRP- $F_{2}$ design, each $G_{3}$ family is generated by selfing from a different $G_{2 R}$ individual. These will differ in polygenic value with standardized polygenic variance between the $G_{3}$ families equal to the heritability $\left(h^{2}\right)$ of the trait in the $G_{2}$ generation plus a small dominance component [30]. This has a strong effect on the $\mathrm{SE}(\mathrm{D})$. In the absence of a polygenic effect, and using the previous notation, we have

$$
\mathrm{D}=(1 / 2)(\mathrm{A}+\mathrm{B}-\mathrm{C}-\mathrm{D}+\mathrm{E}+\mathrm{F}-\mathrm{G}-\mathrm{H})
$$

Four families types are represented (Table 2). Groups $\mathrm{A}$ and $\mathrm{E}$ are derived from Family type 1; Groups B and F from Family type 2; groups $\mathrm{C}$ and $\mathrm{G}$ from Family type 3 and groups $\mathrm{D}$ and $\mathrm{H}$ from Family type 4 . Then, in the presence of a polygenic effect, to each of the groups, in addition to the expected genotypic value, we need to add a polygenic value taken from a normal distribution with mean 0 and variance $h^{2}$.

Letting $P_{1}, P_{2}, P_{3}, P_{4}$ be the polygenic effects of Families $1,2,3$, 4 respectively, we have:

$$
\begin{gathered}
\mathrm{D}^{\prime}=(1 / 2)\left(\mathrm{A}+\mathrm{P}_{1}+\mathrm{B}+\mathrm{P}_{2}-\mathrm{C}-\mathrm{P}_{3}-\mathrm{D}-\mathrm{P}_{4}+\mathrm{E}+\mathrm{P}_{1}\right. \\
\left.+\mathrm{F}+\mathrm{P}_{2}-\mathrm{G}-\mathrm{P}_{3}-\mathrm{H}-\mathrm{P}_{4}\right) \\
=(1 / 2)\left(A+B-C-D+E+F-G-H+2 P_{1}\right. \\
\left.+2 P_{2}-2 P_{3}-2 P_{4}\right)
\end{gathered}
$$

As before

$$
\begin{gathered}
\sigma_{\mathrm{A}}^{2}=\sigma_{\mathrm{B}}^{2}=\sigma_{\mathrm{C}}^{2}=\sigma_{\mathrm{D}}^{2}=1 /\left(\mathrm{N}_{\mathrm{G} 3} / 16\right)=16 / \mathrm{N}_{\mathrm{G} 3} \\
\sigma_{\mathrm{E}}^{2}=\sigma_{\mathrm{H}}^{2}=1 /\left(\mathrm{N}_{\mathrm{TG} 3} / 8\right)=8 / \mathrm{N}_{\mathrm{G} 3} \\
\sigma^{2}\left(2 P_{1}\right)=\sigma^{2}\left(2 P_{2}\right)=\sigma^{2}\left(2 P_{3}\right)=\sigma^{2}\left(2 P_{4}\right)=4 h^{2} / k, \text { where } \mathrm{k} \text { is }
\end{gathered}
$$
the average number of replicate families of each type.

Then

$$
\begin{aligned}
& \mathrm{SE}^{2}\left(\mathrm{D}^{\prime}\right)=(1 / 4)\left(4 * 16 / \mathrm{N}_{\mathrm{G} 3}+4 * 8 / \mathrm{N}_{\mathrm{G} 3}+4 * 4 \mathrm{~h}^{2} / \mathrm{k}\right) \\
& =\left(16 / \mathrm{N}_{\mathrm{G} 3}+8 / \mathrm{N}_{\mathrm{G} 3}+4 \mathrm{~h}^{2} / \mathrm{k}\right)=24 / \mathrm{N}_{\mathrm{G} 3}+4 \mathrm{~h}^{2} / \mathrm{k}
\end{aligned}
$$

The polygenic component has a powerful effect. For example, if $\mathrm{N}_{\mathrm{G} 3}=1000, \mathrm{n}=50$, then $\mathrm{k}=(1000 / 50) / 4=5$, Then if $\mathrm{h}^{2}=0.25$, we have $\mathrm{SE}^{2}(\mathrm{D})=24 / 1000=0.024$ in $\mathrm{ab}-$ sence of a polygenic effect; while the polygenic effect will add $4 * 0.25 / 5=0.20$, to give $\mathrm{SE}^{2}\left(\mathrm{D}^{\prime}\right)=0.224$. For $\mathrm{SE}^{2}\left(\mathrm{D}^{\prime}\right)$ to equal 0.024 in the presence of a polygenic effect, we would need to increase $\mathrm{N}_{\mathrm{G} 3}$ tenfold, from 1000 to 10,000, giving $\mathrm{k}=50$, and $\mathrm{SE}^{2}\left(\mathrm{D}^{\prime}\right)=24 / 10,000+4 \mathrm{~h}^{2} / 50=0.0224$. 


\section{(xv) Using non-recombinant progeny to correct for polygenic effects}

To deal with polygenic effects in a more effective manner, we propose to use the non-recombinant group of each family as an estimate of the family polygenic effect, and express the recombinant groups as deviations from the nonrecombinant group. Examination of Table 2 shows that there are two classes of non-recombinant groups. For Families 1 and 3, the non-recombinant groups have genotype: $\mathrm{M}_{1} \mathrm{QM}_{2} / \mathrm{M}_{1} \mathrm{QM}_{2}$, with genotype values $+\mathrm{d}$; for Families 2 and 4 , the non-recombinant groups have genotype $\mathrm{m}_{1} \mathrm{qm}_{2} /$ $\mathrm{m}_{1} \mathrm{qm}_{2}$, with genotype values $-\mathrm{d}$. Thus, to bring all nonrecombinant families to the same expectation, we need to estimate $d$ from the previous mapping experiment that defined the original QTL, and correct Families 2 and 4 for the effect of the QTN by adding $2 d$ to the nonrecombinant groups of these families. When this is done, the variation among non-recombinant groups of the different families, will be due to polygenic variation alone. Thus, the mean of the non-recombinant group will represent the polygenic effect of the family and will be common to all genotype groups within the family. Consequently, the expected deviation of the recombinant groups from the nonrecombinant group mean will be due to genotype at the target QTL only, and not due to polygenic effects.

Although the expected polygenic effect of the nonrecombinant group and of the recombinant groups is the same, the mean of a non-recombinant group will have a sampling variance, depending on the number of individuals in the group. Since proportion of total family in the nonrecombinant groups is $1 / 16$, this will equal $16 / \mathrm{N}_{\mathrm{G} 3}$. Note, in this case, $\mathrm{k}$ is not relevant as it does not make any difference how many subfamilies are within a given family, sampling variance of the non-recombinant groups will depend on the total population size only, and not on how it is divided among replicate families.

If we let $Q_{1}, Q_{2}, Q_{3}, Q_{4}$, be the sampling deviation of the non-recombinant group from expectation, we have

$$
\begin{gathered}
\mathrm{D}=(1 / 2)\left(\mathrm{A}+\mathrm{Q}_{1}+\mathrm{B}+\mathrm{Q}_{2}-\mathrm{C}-\mathrm{Q}_{3}-\mathrm{D}-\mathrm{Q}_{4}\right. \\
\left.+\mathrm{E}+\mathrm{Q}_{1}+\mathrm{F}+\mathrm{Q}_{2}-\mathrm{G}-\mathrm{Q}_{3}-\mathrm{H}-\mathrm{Q}_{4}\right) \\
=(1 / 2)(\mathrm{A}+\mathrm{B}-\mathrm{C}-\mathrm{D}+\mathrm{E}+\mathrm{F}-\mathrm{G}-\mathrm{H} \\
\left.+2 \mathrm{Q}_{1}+2 \mathrm{Q}_{2}-2 \mathrm{Q}_{3}-2 \mathrm{Q}_{4}\right)
\end{gathered}
$$

Where, as before

$$
\begin{gathered}
\sigma_{\mathrm{A}}^{2}=\sigma_{\mathrm{B}}^{2}=\sigma_{\mathrm{C}}^{2}=\sigma_{\mathrm{D}}^{2}=1 /\left(\mathrm{N}_{\mathrm{G} 3} / 16\right)=16 / \mathrm{N}_{\mathrm{G} 3} \\
\sigma_{\mathrm{E}}^{2}=\sigma_{\mathrm{H}}^{2}=1 /\left(\mathrm{N}_{\mathrm{G} 3} / 8\right)=8 / \mathrm{N}_{\mathrm{G} 3} \\
\sigma^{2}\left(2 Q_{1}\right)=\sigma^{2}\left(2 Q_{2}\right)=\sigma^{2}\left(2 Q_{3}\right)=\sigma^{2}\left(2 Q_{4}\right)=4 * 16 / \mathrm{N}_{\mathrm{G} 3} \\
\text { Then } \mathrm{SE}^{2}(\mathrm{D})=(1 / 4)\left(4 * 16 / \mathrm{N}_{\mathrm{G} 3}+4 * 8 / \mathrm{N}_{\mathrm{G} 3}+4 * 4 * 16 /\right. \\
\left.\mathrm{N}_{\mathrm{G} 3}\right)=\left(16 / \mathrm{N}_{\mathrm{G} 3}+8 / \mathrm{N}_{\mathrm{G} 3}+64 / \mathrm{N}_{\mathrm{G} 3}\right)=88 / \mathrm{N}_{\mathrm{G} 3}
\end{gathered}
$$

Substituting and solving for $\mathrm{N}$ we have

$$
\mathrm{Z}_{\alpha / 2}=3 \mathrm{~d} /\left(88 / \mathrm{N}_{\mathrm{G} 3}\right)^{0.5}
$$

And solving for $\mathrm{N}_{\mathrm{G} 3}$, we have

$\mathrm{N}_{\mathrm{G} 3}=88 \mathrm{Z}_{\alpha / 2}^{2} / 9 \mathrm{~d}^{2}=9.88 \mathrm{Z}_{\alpha / 2}^{2} / \mathrm{d}^{2}$ for one side of the CI, and twice this, $19.76 \mathrm{Z}_{\alpha / 2}^{2} / \mathrm{d}^{2}$ for two-sided CI.

If we set $\alpha=0.05, d=0.2$ as in our example, we have $Z_{\alpha / 2}=1.96$, and total $G_{3}$ population required for a twoside $\mathrm{CI}, \mathrm{N}_{\mathrm{G} 3}=1897.75$. This can be compared to the corresponding value $\mathrm{N}_{\mathrm{G} 3}=512.85$ in the absence of polygenic effects. Since all other numbers in the analysis are functions of $\mathrm{N}_{\mathrm{G} 3}$, the presence of polygenic effects of magnitude $\mathrm{h}^{2}=0.25$, increases required populations sizes 3.7-fold all down the line. Relative to a standard $F_{2}$ design, TRP- $F_{2}$ population sizes for equivalent power as a proportion of the required $\mathrm{F}_{2}$ population would increase from 0.288 for $\mathrm{c}=0.1, \mathrm{~s}=2$ in the absence of polygenic effects, to 1.068 in their presence, i.e., no savings. For c $=0.01, \mathrm{~s}=2$, however, relative savings would be 0.152 , which is still appreciable.

\section{Simulation}

The above calculations assume a saturated marker map, and saturation of the QTL by points of recombination. A simulation study was carried out to study the effect of marker spacing, and number of $G_{2 R}$ families (i.e., number of randomly spaced points of recombination per target CI) on the Standard Error of QTN map location (SEQTN). For simplicity we simulated a TRP-BC (backcross) design, and assumed absence of polygenic effects.

As before, we assume that conventional QTL mapping in a $\mathrm{BC}, \mathrm{F}_{2}$ or AIL population has detected a QTL of interest with a $95 \%$ confidence interval (CI) defined by a pair of flanking upstream and downstream markers, denoted $M_{U}$ and $M_{D}$, respectively. A very large set of evenly spaced ordered makers, denoted $M_{1}$ to $M_{k}$ spanning the interval $M_{U}$ to $M_{D}$ is available, and haplotypes of the parental lines (denoted the $G_{1}$ generation) with respect to these markers are known. In the proposed scheme, the original or a new mapping population (the $G_{2}$ generation) is genotyped for the $M_{U}-M_{D}$ marker pair, and $G_{2 R}$ individuals carrying recombinant chromosomes across this region (i.e., $m_{U}-M_{D}$ and $M_{U}-m_{D}$ ) are identified. These are backcrossed to one of the original founder lines, and a large simulated BC progeny population (the $G_{3}$ generation) is formed, consisting of a number of $G_{2 R}$ families, and genotyped for the marker set spanning the QTL. A QTN is simulated at a specific location in the QTL, and the marker showing the largest difference between alternative marker genotypes is identified as the estimated QTN location. The distance between the estimated QTN location and the simulated location was determined in units of the initial QTL, and 
the accuracy of map location was evaluated as the SEQTN. For each combination of parameters, 1000 Monte Carlo simulations were run.

To investigate the effect of population size $(\mathrm{N})$, number of internal markers $(\mathrm{k})$ and QTN location (L) on SEQTN we set: $\mathrm{N}=1000,3000,5000,7000,9000,11000$; $\mathrm{k}=2,5,10,23,30,40,50$ ( $\mathrm{k}$ does not include the flanking $M_{U}$ and $M_{D}$ markers, e. g., $k=2$ represents a total of 4 markers, the two flanking markers and two internal markers); allele substitution effect in standardized units, $\mathrm{d}=0.2$; number of $\mathrm{G}_{2 \mathrm{R}}$ families, $\mathrm{F}=25$; QTN location, $\mathrm{L}=$ $0.57,0.77$, again taking the width of the $\mathrm{CI}=1.0$ as the unit of measure. Thus, $\mathrm{L}=0.57$ is a bit distal to the center of the QTL, and $\mathrm{L}=77$ is slightly distal to the threequarter mark. QTN positions and the $\mathrm{k}=23$ marker number were chosen to ensure that in no instance did marker position and simulated QTN position coincide.

To investigate effect of number of families within a QTL on SEQTN we set $\mathrm{N}=3000,11000 ; \mathrm{F}=500,250,100,50$, 25,$10 ; \mathrm{L}=0.57 ; \mathrm{k}$ and $\mathrm{d}$ as before.

The simulation results were obtained as SEQTN, while the results of the deterministic analysis are presented as the population size required to achieve a given factor of QTL reduction, s. To compare the two approaches we converted both of their outputs to the achieved reduction factor, s. For SEQTN, we assumed that the new confidence interval of QTN location would equal 4*SEQTN (i.e., two standard deviations to each side). Thus, taking the original $\mathrm{QTL}=1.0$, and the new $\mathrm{QTL}=4(\mathrm{SEQTN})$, the reduction factor would be $s=1 / 4(\mathrm{SEQTN})$. For the deterministic analysis, we have $\mathrm{N}_{\mathrm{TG} 3}=\mathrm{sN}_{\mathrm{G} 3}$, so that $\mathrm{s}=$ $\mathrm{N}_{\mathrm{TG} 3} / \mathrm{N}_{\mathrm{G} 3}$.

For example, in the simulation, at $\mathrm{N}=7000(\mathrm{~L}=0.57)$, we obtain SEQTN $=0.0575$. Then $s=1 / 4(\mathrm{SEQTN})=4.35$. In the deterministic analysis of the TRP- $\mathrm{BC}$ design, $\mathrm{N}_{\mathrm{G} 3}=$ 1536.64 (see Results). Then, $\mathrm{s}=7000 / 1536.64=4.56$.

\section{Results}

As shown in Methods, the basic parameter determining the required numbers of $G_{3}$ progeny and $G_{2}$ parents under the TRP design, is $\mathrm{N}_{\mathrm{G} 3}$, the number of $\mathrm{G}_{3}$ individuals needed to define a single (1- $\alpha)$ CI for given allele substitution effect, d. For a $95 \% \mathrm{CI}$ in the absence of polygenic effects, we derived the expression $\mathrm{N}_{\mathrm{G} 3}=5.34 \mathrm{z}_{\alpha / 2}^{2} / \mathrm{d}^{2}$. Taking $95 \% \mathrm{CI}$ as the standard, $\mathrm{z}_{\alpha / 2}=1.96$, and folding this into the constant, we have $\mathrm{N}_{\mathrm{G} 3}=20.51 / \mathrm{d}^{2}$. This shows starkly that $\mathrm{N}_{\mathrm{G} 3}$ will be very sensitive to the allele substitution effect, d, e.g., in absence of polygenic effects, $\mathrm{N}_{\mathrm{G} 3}=$ 2051.0, 512.75, and 227.9 for $\mathrm{d}=0.1,0.2$ and 0.3, respectively. We stress again that these numbers are independent of the size of the original QTL (C) or of the target subQTL (c), or the reduction factor (s). It makes no difference if the reduction is from $20 \mathrm{cM}$ to $2 \mathrm{cM}$, or from $2 \mathrm{cM}$ to $0.2 \mathrm{cM}, \mathrm{N}_{\mathrm{G} 3}$ will be the same. The same holds true in the presence of polygenic effects, except that in this case, the basic expression for $\mathrm{N}_{\mathrm{G} 3}=75.91 / \mathrm{d}^{2}$

The total $\mathrm{G}_{3}$ population, $\mathrm{N}_{\mathrm{TG} 3}$ required for mapping under TRP, depends solely on $\mathrm{N}_{\mathrm{G} 3}$ and $\mathrm{s}$, the desired reduction-factor in QTL size. A five-fold reduction means that the original QTL will be divided into 5 sub-QTL. This will require the same number, $\mathrm{N}_{\mathrm{G} 3}$ of individuals for each of the sub-QTL. Consequently, $\mathrm{N}_{\mathrm{TG} 3}=\mathrm{sN}_{\mathrm{G} 3}$, where $\mathrm{s}$ is the number of sub-QTL into which we divide our original QTL.

The total $G_{2}$ population required to produce the $G_{3}$ population in absence of polygenic effects, depends on $\mathrm{N}_{\mathrm{G} 3}$, and on the reproductive potential (n) and target interval (c) as follows, $\mathrm{N}_{\mathrm{G} 2}=\mathrm{N}_{\mathrm{G} 3} / 2 \mathrm{nc}(1-\mathrm{c})$. Thus, it stands in proportion to $1 / 2 \mathrm{nc}(1-\mathrm{c})$. Assuming, $\mathrm{n}=50,1 / 2 \mathrm{nc}(1-\mathrm{c})$ will be quite small when $\mathrm{c}$ is large, e.g., for $\mathrm{C}=0.2 \mathrm{M}$, $\mathrm{c}=0.1 \mathrm{M}, 1 / 2 \mathrm{nc}(1-\mathrm{c})=0.111$ and $\mathrm{N}_{\mathrm{G} 2}=56.98$ indeed very small $(5 \%)$ relative to $\mathrm{N}_{\mathrm{TG} 3}=1026$ for this case (Table 3). However, $1 / 2 \mathrm{nc}(1-\mathrm{c})$ will assume larger values when $\mathrm{c}$ is small; e.g., for $\mathrm{C}=0.1, \mathrm{c}=0.01,1 / 2 \mathrm{nc}(1-\mathrm{c})=$ $0.99, \mathrm{~N}_{\mathrm{G} 2}=507.72$ and $\mathrm{N}_{\mathrm{TG} 3}=5129(10 \%)$; and for $\mathrm{C}=$ 0.2. $\mathrm{c}=0.002,1 / 2 \mathrm{nc}(1-\mathrm{c})=5.01$, and $\mathrm{N}_{\mathrm{G} 2}=2569$ and $\mathrm{N}_{\mathrm{TG} 3}=5129,(50 \%)$.

Table 3 shows population size required for the $G_{2}$ and $\mathrm{G}_{3}$ stages of the TRP design and total numbers across both generations as a function of the width of the original QTL (C), the target sub-QTL (c), and the reduction factor, s, on the assumptions of no polygenic effect, $\mathrm{d}=0.2, \mathrm{n}=50$ and $\alpha=0.05$. Population size for TRP designs relative to $F_{2}$ designs range from 0.289 for initial $\mathrm{CI}$ of $0.2 \mathrm{M}$ to 0.041 for initial CI of $0.02 \mathrm{M}$. Thus, the clear conclusion is that the TRP design will be most

Table 3 Population size for TRP-F2 design by width of initial QTL and target QTL, polygenic effect absent ${ }^{1}$

\begin{tabular}{llllllll}
\hline $\mathbf{C}$ & $\mathbf{S}$ & $\mathbf{C}$ & $\mathbf{N}_{\text {TG3 }}$ & $\mathbf{N}_{\mathbf{G 2}}$ & $\mathbf{N}_{\text {TRP }}$ & $\mathbf{N}_{\mathbf{F 2}}$ & $\mathbf{N}_{\text {TRP }} / \mathbf{N}_{\mathbf{F 2}}$ \\
\hline 0.20 & 2 & 0.100 & 1026 & 57 & 1083 & 3750 & 0.289 \\
0.20 & 4 & 0.050 & 2051 & 108 & 2159 & 7500 & 0.288 \\
0.20 & 10 & 0.020 & 5129 & 261 & 5390 & 18750 & 0.287 \\
0.10 & 2 & 0.050 & 1026 & 108 & 1134 & 7500 & 0.151 \\
0.10 & 10 & 0.010 & 5129 & 517 & 5646 & 37500 & 0.151 \\
0.05 & 2 & 0.025 & 1026 & 211 & 1237 & 15000 & 0.082 \\
0.05 & 5 & 0.010 & 2564 & 517 & 3081 & 37500 & 0.082 \\
0.05 & 10 & 0.005 & 5129 & 1029 & 6158 & 75000 & 0.082 \\
0.02 & 2 & 0.010 & 1026 & 517 & 1543 & 37500 & 0.041 \\
0.02 & 4 & 0.005 & 2051 & 1046 & 3097 & 75000 & 0.041 \\
0.02 & 10 & 0.002 & 5129 & 2564 & 7693 & 187500 & 0.041 \\
\hline Ab & 2 & &
\end{tabular}

${ }^{1}$ Abbreviations: $C$, the original QTL in Morgans; $s$, the reduction factor; $C_{\text {, }}$ target QTL in Morgans; $\mathrm{N}_{\mathrm{TG} 3}$, total size of $\mathrm{G}_{3}$ population; $\mathrm{N}_{\mathrm{G} 2}$, total size of $\mathrm{G}_{2}$ population. $\mathrm{N}_{\mathrm{TRP}}$, total number required across $\mathrm{G}_{2}$ and $\mathrm{G}_{3}$ populations; $\mathrm{N}_{\mathrm{F} 2}$, population size for equivalent QTL width using an $F_{2}$ design. Assumptions: polygenic effect absent; standardized allele substitution effect, $d=0.2$; reproductive potential of the $G_{2}$ generation, $n=50$; and confidence level set at $(1-a)=95 \%$ 
useful when the initial CI of the QTL has been brought to fairly high resolution already, and the desired step is ultra-high resolution. Within a given initial CI, the relative effectiveness of the TRP designs compared to the $\mathrm{F}_{2}$ designs does not depend on the target CI. Of course, the actual required numbers vary considerably, as seen in Table 3. But the relative numbers required remain the same.

The table shows clearly that $\mathrm{N}_{\mathrm{TG} 3}$ varies directly with and depends solely on the reduction factor, s; while $\mathrm{N}_{\mathrm{G} 2}$ varies inversely with the original QTL and target subQTL size, and directly with the reduction factor.

In contrast to the required number of $G_{3}$ and $G_{2 R}$ individuals, which is a function only of the reduction factor, the total number of $G_{2}$ individuals depends strongly on the target CI. This is due to the fact that it requires, for example, ten times as many total $G_{2}$ individuals to uncover a given number of $G_{2 R}$ individuals in a region of $0.02 \mathrm{M}$, as compared to a region of $0.2 \mathrm{M}$. Thus, the number of $G_{2}$ individuals ranges from $5 \%$ of the number of $\mathrm{G}_{2}$ individuals when initial $\mathrm{CI}$ is $0.2 \mathrm{M}$; to ten times this, or $50 \%$ when initial $\mathrm{CI}$ is $0.02 \mathrm{M}$.

In the absence of polygenic effects, the TRP delivers major reductions in mapping population size relative to a standard $F_{2}$ design, depending on the initial QTL size. This is particularly evident for very high resolution, $\mathrm{c}=$ $0.01 \mathrm{M}$ or $0.002 \mathrm{M}$, where the TRP ostensibly delivers ultra-high resolution at very acceptable population sizes, while the $\mathrm{F}_{2}$ design requires very high numbers for mapping at this resolution. Sadly, this fine performance is markedly reduced when polygenic effects are taken into account (Table 4). In this case, the relative effectiveness of the TRP design depends strongly on the initial QTL

Table 4 Population size for TRP-F2 design, polygenic effect present ${ }^{1}$

\begin{tabular}{llllllll}
\hline $\mathbf{C}$ & $\mathbf{S}$ & $\mathbf{C}$ & $\mathbf{N}_{\text {TG3 }}$ & $\mathbf{N}_{\mathbf{G} 2}$ & $\mathbf{N}_{\text {TRP }}$ & $\mathbf{N}_{\mathbf{F} 2}$ & $\mathbf{N}_{\text {TRP }} / \mathbf{N}_{\mathbf{F 2}}$ \\
\hline 0.20 & 2 & 0.100 & 3796 & 211 & 4007 & 3750 & 1.068 \\
0.20 & 4 & 0.050 & 7591 & 400 & 7991 & 7500 & 1.065 \\
0.20 & 10 & 0.020 & 18978 & 968 & 19946 & 18750 & 1.064 \\
0.10 & 2 & 0.050 & 3796 & 400 & 4196 & 7500 & 0.559 \\
0.10 & 10 & 0.010 & 18978 & 1917 & 20895 & 37500 & 0.557 \\
0.05 & 2 & 0.025 & 3796 & 779 & 4575 & 15000 & 0.305 \\
0.05 & 5 & 0.010 & 9489 & 1917 & 11406 & 37500 & 0.304 \\
0.05 & 10 & 0.005 & 18978 & 3814 & 22793 & 75000 & 0.304 \\
0.02 & 2 & 0.010 & 3796 & 1917 & 5713 & 37500 & 0.152 \\
0.02 & 4 & 0.005 & 7591 & 3814 & 11406 & 75000 & 0.152 \\
0.02 & 10 & 0.002 & 18978 & 9508 & 28486 & 187500 & 0.152
\end{tabular}

${ }^{1}$ Abbreviations: $C$, the original QTL in Morgans; $s$, the reduction factor; $c$, target QTL in Morgans; $\mathrm{N}_{\mathrm{TG}}$, total size of $\mathrm{G}_{3}$ population; $\mathrm{N}_{\mathrm{G} 2}$, total size of $\mathrm{G}_{2}$ population. $\mathrm{N}_{\mathrm{TRP}}$, total number required across $\mathrm{G}_{2}$ and $\mathrm{G}_{3}$ populations; $\mathrm{N}_{\mathrm{F} 2}$, population size for equivalent $Q T L$ width using an $F_{2}$ design. Assumptions: polygenic effect present; standardized allele substitution effect, $d=0.2$; reproductive potential of the $G_{2}$ generation, $n=50$; and confidence level set at $(1-a)=95 \%$ start width. Indeed, when start point is at $\mathrm{C}=0.2$, the TRP design required a bit larger population size than an $F_{2}$. When the initial interval is small (e.g., 0.05 or 0.02 $\mathrm{M})$, TRP requires only about $15 \%$ the population size of an F2 for equivalent mapping precision. In this case, TRP can close the gap to $0.01 \mathrm{M}$ with manageable numbers (11,406 and 5,713, for $\mathrm{C}=0.05$ and $\mathrm{C}=0.02$, respectively).

For species with short generation interval (annual plants, mice) a two- stage TRP can start with a large initial CI, say $\mathrm{C}=0.2 \mathrm{M}$, and yet reach $\mathrm{c}=0.01$ in two steps, with acceptable total population numbers. For example, starting with $\mathrm{C}=0.2 \mathrm{M}$, first stage might reduce four-fold to $0.05 \mathrm{M}$ requiring $\mathrm{N}_{\mathrm{TRP}}=7991$; second stage would reduce four-fold again to $0.0125 \mathrm{M}$ requiring $\mathrm{N}_{\text {TRP }}=7991$, total 15,982 , spread fairly equally over two years; while $F_{2}$ would require 30,000 .

\section{The number of recombination points per sub-QTL}

The number of $G_{2 R}$ individuals needed to produce the required number of $G_{3}$ progeny for each sub-CI of size c, is:

$$
\mathrm{N}_{\mathrm{G} 2 \mathrm{R}}=\mathrm{N}_{\mathrm{G} 3} / \mathrm{n}
$$

where

$\mathrm{n}$ is the number of progeny that are produced by selfing each $G_{2 R}$ parent.

Continuing our example, and assuming $n=50$, then $\mathrm{N}_{\mathrm{G} 2 \mathrm{R}}=512.75 / 50=10.26$. The $\mathrm{G}_{3}$ progeny of each $\mathrm{G}_{2 \mathrm{R}}$ parent, present a single point of recombination per subQTL Thus, in our example, there will be on average 10.26 points of recombination within each sub-QTL. The corresponding number when polygenic effects are present, is 37.93. These numbers are constants that depend only on $\mathrm{N}_{\mathrm{G} 3}$, and are not affected by $\mathrm{C}$, c, or $\mathrm{s}$. The number of recombination points per sub-QTL when taking polygenic effects into account is quite large, and in view of the simulation results, would seem more than sufficient so as not to be a limiting factor in the precision of setting QTL confidence intervals by the TRP design.

\section{Simulation}

Table 5 shows simulation results with respect to effect of mapping population size $(\mathrm{N})$, number of markers spanning the QTL $(\mathrm{k})$ and marker position within the QTL (L). Results are shown as the Standard error of estimated QTN location relative to the simulated location (SEQTN). Also shown are comparisons of reduction factor (s) as obtained from the simulation (sSIM) and as obtained from the deterministic analysis (sDET). Considering first the effect of marker number, except for $\mathrm{N}=1000$, at both QTN positions SEQTN is reduced by each step from $\mathrm{k}=2$ to $k=23$, but there is no further decrease in going from 
Table 5 Standard error of estimated QTN location by simulation, as a function of $\mathrm{G}_{3}$ population size (N) ${ }^{1}$

\begin{tabular}{|c|c|c|c|c|c|c|c|c|c|}
\hline $\mathrm{N}$ & $k=2$ & 5 & 10 & 23 & 30 & 40 & 50 & sSIM & sDET \\
\hline \multicolumn{10}{|c|}{$L=0.57$} \\
\hline 1000 & 2.0700 & 0.7220 & 0.3340 & 0.2030 & 0.1890 & 0.1820 & 0.1820 & 1.37 & 0.65 \\
\hline 3000 & 0.7640 & 0.1180 & 0.0974 & 0.0959 & 0.0936 & 0.0921 & 0.0926 & 2.70 & 1.95 \\
\hline 5000 & 0.4200 & 0.0993 & 0.0758 & 0.0734 & 0.0711 & 0.0728 & 0.0712 & 3.51 & 3.25 \\
\hline 7000 & 0.1270 & 0.0905 & 0.0659 & 0.0580 & 0.0569 & 0.0581 & 0.0575 & 4.35 & 4.56 \\
\hline 9000 & 0.1140 & 0.0895 & 0.0587 & 0.0500 & 0.0493 & 0.0491 & 0.0485 & 5.15 & 5.86 \\
\hline 11000 & 0.1200 & 0.0859 & 0.0575 & 0.0499 & 0.0494 & 0.0472 & 0.0453 & 5.52 & 7.16 \\
\hline \multicolumn{10}{|c|}{$L=0.77$} \\
\hline 1000 & 1.8100 & 0.3700 & 0.1890 & 0.1730 & 0.1680 & 0.1710 & 0.1700 & 1.47 & 0.65 \\
\hline 3000 & 0.4950 & 0.1090 & 0.0964 & 0.0909 & 0.0894 & 0.0900 & 0.0883 & 2.83 & 1.95 \\
\hline 5000 & 0.1380 & 0.0943 & 0.0723 & 0.0691 & 0.0680 & 0.0681 & 0.0672 & 3.72 & 3.25 \\
\hline 7000 & 0.1330 & 0.0864 & 0.0659 & 0.0570 & 0.0551 & 0.0553 & 0.0559 & 4.47 & 4.56 \\
\hline 9000 & 0.1310 & 0.0828 & 0.0597 & 0.0499 & 0.0489 & 0.0492 & 0.0494 & 5.06 & 5.86 \\
\hline 11000 & 0.1280 & 0.0844 & 0.0567 & 0.0490 & 0.0461 & 0.0458 & 0.0460 & 5.43 & 7.16 \\
\hline
\end{tabular}

${ }^{1}$ Abbreviations and assumptions: Standard error of estimated QTN location (SEQTN) by simulation, as a function of G3 population size (N), family size, (I); location of the QTN within its confidence interval (L) and number of markers spanning the QTL (k). sSIM, reduction factor according to the simulation analysis; sDET, reduction factor according to the deterministic analysis. Standardized allele substitution effect at the $Q T N=0.2 ; n u m b e r$ of $G_{2 R}$ families, $F=25$

$\mathrm{k}=23$ to $\mathrm{k}=50$. (For $\mathrm{N}=1000$ there is a further reduction going from $\mathrm{k}=23$ to $\mathrm{k}=30$, but not beyond this). This is somewhat surprising, as we would expect an interaction between population size and marker density. The lack of such interaction is probably due to the fact that number of families was set at 25 , so that the number of recombination points across the QTL was a limiting factor in reducing SEQTN by increase in marker density.

Table 6 Standard error of estimated QTN location by simulation, as a function of number of $G_{2 R}$ families $(F)^{1}$

\begin{tabular}{llllllll}
\hline $\mathbf{F}$ & $\mathbf{k}=\mathbf{2}$ & $\mathbf{5}$ & $\mathbf{1 0}$ & $\mathbf{2 3}$ & $\mathbf{3 0}$ & $\mathbf{4 0}$ & $\mathbf{5 0}$ \\
\hline $\mathrm{N}=3000$ & & & & & & \\
500 & 0.7270 & 0.2190 & 0.0889 & 0.0850 & 0.0847 & 0.0841 & 0.0844 \\
250 & 0.7420 & 0.1130 & 0.0851 & 0.0863 & 0.0813 & 0.0817 & 0.0819 \\
100 & 0.4200 & 0.1120 & 0.0913 & 0.0855 & 0.0851 & 0.0868 & 0.0863 \\
50 & 0.8120 & 0.2110 & 0.1250 & 0.0908 & 0.0939 & 0.0957 & 0.0925 \\
25 & 0.6800 & 0.1670 & 0.1170 & 0.1030 & 0.1030 & 0.1000 & 0.1020 \\
10 & 0.8340 & 0.3410 & 0.1970 & 0.1320 & 0.1270 & 0.1240 & 0.1230 \\
$\mathrm{~N}=11000$ & & & & & & \\
500 & 0.0669 & 0.0785 & 0.0404 & 0.0298 & 0.0283 & 0.0256 & 0.0237 \\
250 & 0.0684 & 0.0784 & 0.0380 & 0.0306 & 0.0285 & 0.0267 & 0.0252 \\
100 & 0.0867 & 0.0791 & 0.0412 & 0.0326 & 0.0307 & 0.0293 & 0.0285 \\
50 & 0.1030 & 0.0818 & 0.0439 & 0.0347 & 0.0346 & 0.0328 & 0.0306 \\
25 & 0.1150 & 0.0843 & 0.0552 & 0.0497 & 0.0490 & 0.0496 & 0.0472 \\
10 & 0.4700 & 0.1050 & 0.0896 & 0.0855 & 0.0863 & 0.0855 & 0.0854 \\
\hline
\end{tabular}

${ }^{1}$ Abbreviations and assumptions. Standard error of estimated QTN location by simulation, as a function of number of $G_{2 R}$ families $(F)$ within given total mapping population size, $(\mathrm{N})$, and number of markers spanning the QTL $(\mathrm{k})$. Location of the QTN within its confidence interval $(L=0.57)$; allele substitution effect at the QTN $=0.2$ in standardized units
Each step increase in $\mathrm{N}$, resulted in a decrease in SEQTN. As could be expected, the marginal decrease in SEQTL was less with each additional step, but still appreciable until the last; the gain in going from $\mathrm{N}=9000$ to $\mathrm{N}=11000$ might appear not to be worth the cost. However, this may be a further consequence of the limit of $G_{2 R}$ families to 25 . In practice, increase in $\mathrm{N}$ would be accompanied by an increase in $\mathrm{N}_{\mathrm{G} 2 \mathrm{R}}$, so that the combined effect of both might be appreciable (see further discussion of Table 6).

Placing the QTN closer to the boundary of the QTL $(\mathrm{L}=0.77$ compared to $\mathrm{L}=0.57$ ) gave slightly smaller SEQTL at all population sizes. This was higher for smaller $\mathrm{N}$ and smaller $\mathrm{k}$, and decreased as $\mathrm{N}$ and $\mathrm{k}$ increased. This is an artifact, due to the fact that in the simulation, the estimated QTN position could not fall outside the boundaries of the QTL. Hence, the boundary set an artificial upper limit to the simulated errors, reducing the SEQTN accordingly. However, the effect was small, suggesting that the results for the more central QTN location $(\mathrm{L}=0.57)$ are not affected in a major way by boundary effects.

Table 5 also shows reduction factor (s) achieved at $\mathrm{k}=$ $50, \mathrm{~F}=25$ by the simulation (sSIM) and by the deterministic analysis (sDET). At marker saturation $(k=50)$, correspondence is rather close for intermediate population sizes $(\mathrm{N}=5000$ and $\mathrm{N}=7000)$ but fall off to either side. On the low side ( $\mathrm{N}=1000$ and 3000) this is probably due to the aforementioned boundary effect. This affects the simulation results, placing an upper boundary on the error values; but apparently does not affect the deterministic results. On the high side $(\mathrm{N}=9000$ and 11000) SEQTL for the simulation is probably limited by the small 
number of $G_{2 R}$ parents, and the resulting paucity of recombination points for mapping, while this is not a limitation for the deterministic analyses.

Table 6 shows simulation results with respect to number of $G_{2 R}$ families in interaction with population size and number of markers. Generally, there is a clear and major decrease in SEQTN with increase in number of families for given population size. The largest effect on SEQTL is given by the first step, from $F=10$ to $F=25$, but even at $\mathrm{N}=11000$, each additional step results in a decrease in SEQTN. SEQTN at F $=500$, is just half the SEQTN at F = 25. At $\mathrm{N}=3000$ there appears to be a slight optimum at $\mathrm{F}=250$. This may be due to inverse relation of number of families and number of individuals within families. The expected interaction between population size and marker density can be observed: at $\mathrm{N}=3000$, increase of $\mathrm{k}$ from 30 to 50 does not reduce SEQTN; but at $N=11000$, from $\mathrm{F}=50$ on, there is a clear reduction in SEQTN with increased marker density. Thus, as suggested above, by increasing $\mathrm{F}$ along with $\mathrm{N}$, major reductions in SEQTN may be achieved, even by going beyond $\mathrm{N}=11000$. For $\mathrm{N}=$ 11000 and $F=50$ or more, sSIM is greater than sDET, to an increasing degree with greater $\mathrm{F}$. For example, with $\mathrm{F}=$ $500, \operatorname{sSIM}=10.5$, while $\mathrm{sDET}=7.16$. We do not have an intuitive explanation for this effect.

\section{Discussion}

The TRP is aimed at mapping a specific target QTN, previously assigned to a rather broad confidence interval; to a smaller $\mathrm{CI}$, reduced by some desired factor relative to the original CI. As such, it is a Group II design as defined by Darvasi [2]. A TRP mapping population of size 10,000 individuals can reduce $\mathrm{CI}$ by a factor of 4 or 5 , even for a QTN of relatively small standardized effect $(\mathrm{d}=0.2)$; for a strong QTN $(\mathrm{d}=0.5)$, the same reduction would be provided by a TRP population size under 2000 . A two-stage experiment with four-fold reduction at each stage, would reduce a starting $\mathrm{CI}$ of $20 \mathrm{cM}$ to $5 \mathrm{cM}$ in the first stage, and to $1.25 \mathrm{cM}$ in the second stage. For $\mathrm{d}=0.2$, this would require about 16,000 individuals in two cohorts of 8,000 each. For $d=0.5$ this would be achieved with two cohorts of about 2000 each. Thus, the TRP design provides a useful solution to the challenge of achieving high resolution mapping for a known specific target QTN. A unique property of the TRP design, is the fact that mapping population size required for a given reduction factor is independent of the size of the starting CI. It will be the same whether the starting CI is $20 \mathrm{cM}$ or $2 \mathrm{cM}$. Consequently, at a given mapping population size, the smaller the initial $\mathrm{CI}$, the smaller the final $\mathrm{CI}$ in proportion. For maximum effectiveness, as shown by the simulation, the TRP design should be implemented with at least 30-40 evenly spaced markers and at least 50 to 100 recombination points within the original CI.
When a QTL is mapped to a large CI, it is not possible to tell if the effect is due to a single QTN in the region, or to the summed effect of a number of closely linked QTN. By dividing the initial CI into sub-intervals, each with considerable mapping power, the TRP design can distinguish between an effect localized to a single point in the original $\mathrm{CI}$, indicating that the total effect was produced by a single QTN, and an effect that is spread all through the QTL, indicating that the total effect represents the summed effects of a number of QTN.

For outcrossing species, WGAS appears to provide a satisfactory solution to the challenge of high resolution mapping of QTN with appreciable effects. This option is obviously not available for high resolution mapping in pure lines of selfing species, or inbred lines of outcrossing species. Although there are a plethora of Group I designs that can provide high resolution mapping across the entire genome (reviewed in Background), with the exception of the AIL design [3] these are all based on specialized resources specifically constructed for high resolution mapping and are perforce limited to the QTL segregating among the founder lines of the resource. For Group II designs that deal with a previously mapped QTL on an ad hoc basis, the choice of designs is limited to the ICSC and RPT designs. The TRP design is an addition to this group. Strictly speaking, the NIL design [9] is not a procedure for high or ultra-high resolution mapping, since the isolated donor segments will likely be in the range 10-20 cM. However, any of the NIL sublines, carrying a QTL of interest would be a superb start point for subsequent application of the ICSC, RPT or TRP designs. There is no doubt that when applicable the ICSC design is a very effective means for high resolution mapping, with minimal requirements for population size. The limitation of the ICSC design is the large number of backcross generations required to generate the series of congenic strains spanning the original CI. This is not a major limitation for species such as the mouse with rapid reproduction cycles; but it is a major limitation for the many plant species that have a single growing season a year. Selection within each backcross step for individuals carrying the least amount of donor genome, could probably reduce the number of backcross steps by one or two generations. The RPT design was presented only briefly in [2] and does not appear to have been subjected to detailed analysis, or to have been widely applied. It appears to be very similar to the TRP design proposed and analyzed here. In both designs, individuals that are recombinant within the original CI are chosen as parents of the mapping population. The major difference is that the RPT design works with a limited number of families, each representing one of a laddered series of recombination points spanning the original QTL at $1 \mathrm{cM}$ intervals. Each of the families must be 
sufficiently powerful to give a decisive decision as to its QTL status and in this way determine whether the QTN is upstream or downstream of the recombination point in that family. In the TRP design, these requirements are relaxed, and the only requirement is that the total number of families is sufficient to give adequate coverage of the original QTL by recombination points, and the total number of recombinant progeny across all families is sufficient for high resolution mapping across the original CI. It should also be noted that the RPT design may have to base on a backcross design in order to obtain the very large numbers required for high power of the individual family, while the TRP design works well with an $F_{2}$ design and fewer individuals per family. Since the F2 design is generally more powerful than the $\mathrm{BC}$ design with equivalent numbers (as seen in the present study), this might also favor the TRP. More exact comparison of the two designs remains for deeper analysis of the RPT. However, all in all RPT and TRP can be considered as variants of the same basic design.

\section{Conclusions}

TRP design allows reducing confidence interval of a known target QTL by some desired factor, independent of the original QTL size. The population size required to achieve this depends greatly on the allele substitution effect and also on the polygenic effect and the factor of reduction that was chosen. It is most effective for reducing $\mathrm{CI}$ from high resolution $(\mathrm{CI}=0.02-0.05$ Morgan) to ultra-high resolution (0.002- 0.005 Morgan) since, as opposed to the standard designs, the number of individuals required does not depend strongly on the size of the target CI. Even in the presence of polygenic effects, TRP provides opportunities to achieve CI reduction with a manageable population size where $F_{2}$ and other designs fail. The TRP design also saves greatly in reducing the amount of genotyping required. Thus, the TRP design provides a useful solution to the problem of achieving high and ultra-high-resolution mapping in crosses of inbred or pure lines, where genome wide associations tests are not applicable.

\section{Appendix}

\section{Calculating $\mathrm{N}_{\mathrm{G} 3}$ for the TRP-BC design}

As shown by Weller and Soller [26] if $\mathrm{M}_{1}$ is a marker located at an estimated QTN location, the probability that the CI of QTN location includes the marker $\mathrm{M}_{2}$ located at a remove of $\mathrm{L}$ Morgan from $\mathrm{M}_{1}$, is equal to the probability of obtaining the value

$$
\mathrm{Z}_{\alpha / 2}=\mathrm{D} / \mathrm{SE}(\mathrm{D})
$$

where ,
$\mathrm{Z}_{\alpha / 2}$ is the standard normal variable corresponding to a probability of $\alpha / 2$,

$D=E\left(M_{1}\right)-E\left(M_{2}\right)$, where $E\left(M_{1}\right)$ is the expected effect at $\mathrm{M}_{1}$ (QTN located at the marker), $\mathrm{E}\left(\mathrm{M}_{2}\right)$ is the expected QTN effect at $M_{2}$ (QTL located at a remove from the QTN) considering recombinant individuals only; and $\mathrm{SE}(\mathrm{D})$ is the standard error of $\mathrm{D}$.

From Table 7 it is apparent that there are two marker genotype groups, each of which is composed of a single recombinant marker group. Marker genotype-group $\mathrm{M}_{1} \mathrm{~m}_{1}$ is composed of recombinant genotype-group $\mathrm{A}$ of Table 7 with genotype: $\mathrm{M}_{1} \mathrm{~m}_{2} / \mathrm{m}_{1} \mathrm{~m}_{2}$, having genotypic value $h$; frequency $1 / 4$ of the entire G3 population. Marker genotype-group $\mathrm{M}_{2} \mathrm{~m}_{2}$ is composed of recombinant genotype-group $B$ of Table 7 with genotype: $m_{1} M_{2}$ / $\mathrm{m}_{1} \mathrm{~m}_{2}$, having genotypic value $-\mathrm{d}$; frequency $1 / 4$ of the entire G3 population.

Letting italics denote the mean genotypic value of the corresponding marker genotype group (including recombinant genotypes only), we have

$$
\begin{aligned}
& \mathrm{E}(\mathrm{M} 1)=M_{1} m_{1}-m_{1} m_{1} \\
& \mathrm{E}(\mathrm{M} 2)=m_{2} M_{2}-m_{2} m_{2} \\
& \mathrm{D}=\left(M_{1} m_{1}-m_{1} m_{1}\right)-\left(m_{2} M_{2}-m_{2} m_{2}\right)
\end{aligned}
$$

On this basis, letting $A, B$, represent the genotypic values of the corresponding genotype groups, we have

$$
\begin{aligned}
& M_{1} m_{1}=A-B \\
& M_{2} m_{2}=B-A
\end{aligned}
$$

Substituting in (1) and combining like terms, we obtain

$$
\mathrm{D}=(A-B)-(B-A)=2(A-B)
$$

Substituting genotypic values of the recombinant groups we have

Table 7 Composition of $G_{3}$ population for TRP-BC design ${ }^{1}$

\begin{tabular}{lll}
\hline G progeny & \multicolumn{2}{c}{ G2R parent } \\
\hline \multirow{2}{*}{ Class I } & $M_{1} m_{2} / m_{1} m_{2}$ & $m_{1} M_{2} / m_{1} m_{2}$ \\
& $M_{1} m_{2} / m_{1} m_{2}$ & $m_{1} M_{2} / m_{1} m_{2}$ \\
& $1 / 4 h A$ & $1 / 4-d B$ \\
Class II & $m_{1} m_{2} / m_{1} m_{2}$ & $m_{1} m_{2} / m_{1} m_{2}$ \\
& $1 / 4-d ~ N R$ & $1 / 4-d N R$ \\
\hline
\end{tabular}

${ }^{1}$ Each cell shows a $G_{3}$ progeny group according to Class and the $G_{2 R}$ parent, showing: Marker genotype of the progeny group (above); proportion of the progeny group in the total $G_{3 R}$ population (below-left); genotypic value of the progeny group (below-center); Code designation $(A, B)$ of the progeny group (below-right). Class I, Heterozygous recombinant progeny; Class II,

Homozygous non-recombinant progeny; NR, non-recombinant progeny group not included in the $G_{3 R}$ mapping population; $d$, allele substitution effect in standardized units; $h$, degree of dominance. 


$$
\mathrm{D}=2(\mathrm{~h}-(-\mathrm{d}))=2(\mathrm{~h}+\mathrm{d})
$$

To calculate $\mathrm{SE}(\mathrm{D})$, we assume that variance within the $G_{3}$ families is the same as variance within the $F_{2}$ generation (set to 1.0 for standardization). This is conservative, as the genetic variance within $G_{3} B C$ families will be less than in an $F_{2}$ population, depending on degree of homzoygosity in their $G_{2 R}$ parent. On this basis, we can write:

$$
\sigma_{\mathrm{A}}^{2}=\sigma_{\mathrm{B}}^{2}=1 /\left(\mathrm{N}_{\mathrm{G} 3} / 4\right)=4 / \mathrm{N}_{\mathrm{G} 3}
$$

(as each of these genotype groups comprises 1/4 of the $\mathrm{G}_{3}$ mapping population) of size $\mathrm{N}_{\mathrm{G} 3}$

Then,

$$
\mathrm{SE}^{2}(\mathrm{D})=4\left(4 / \mathrm{N}_{\mathrm{G} 3}+4 / \mathrm{N}_{\mathrm{G} 3}\right)=32 / \mathrm{N}_{\mathrm{G} 3}
$$

Substituting, we have

$$
\begin{aligned}
& Z_{a / 2}=2(\mathrm{~h}+\mathrm{d}) \text {. Assuming } \mathrm{h}=0, \text { we have } \\
& Z_{a / 2}=2 \mathrm{~d} /\left(32 / \mathrm{N}_{\mathrm{G} 3}\right)^{0.5} \text { and solving for } \mathrm{N}_{\mathrm{G} 3} \text { we obtain } \\
& \mathrm{N}_{\mathrm{G} 3}=8 \mathrm{Z}_{\mathrm{a} / 2}{ }^{2} / \mathrm{d}^{2}
\end{aligned}
$$

If we set $\alpha=0.05$ and $d=0.2$, as we did for the TRP-F2 design, we have $Z_{\alpha / 2}=1.96$, and

$$
\mathrm{N}_{\mathrm{G} 3}=768.3
$$

Since the interval between $M_{1}$ and $M_{2}$ defines only half of the CI of QTN location, to cover the entire CI would require twice this

$$
\mathrm{N}_{\mathrm{G} 3}=16 \mathrm{Z}_{\alpha / 2}^{2} / \mathrm{d}^{2}=1536.6
$$

On these assumed values for $\alpha$ and $d$, the basic $G_{3 R}$ population required for $\mathrm{CI}(0.95)=\mathrm{N}_{\mathrm{G} 3}=1536.64$ This number is constant for given $\mathrm{d}$, and $\alpha$, and does not depend on the target size of the confidence interval. The corresponding value for TRP- $\mathrm{F}_{2}$ design is 512.34 . On general principles we would have expected NG3 for TRP-BC with $\mathrm{h}=0$ to be twice that for TRP- $\mathrm{F}_{2}$ (that is, 1024,68). The difference is due to the fact that the mapping population for the TRP- $\mathrm{F}_{2}$ is $75 \%$ of the total population; while the mapping population for the TRP-BC is $50 \%$ of the total population. If we increase the TRP-BC $\mathrm{N}_{\mathrm{G} 3}$ value by $50 \%$ to make up for this we obtain NG3 $=1529.37$, as found.

\section{Abbreviations}

QTN: Quantitative Trait Nucleotide; QTL: Quantitative Trait Locus; TRP: Targeted recombinant Progeny; Cl: Confidence Interval; MAS: Marker assisted selection; MAI: Marker assisted introgression; SNP: Single Nucleotide Polymorphism; WGAS: Whole genome association studies; LD: Linkage disequilibrium; AlL: Advanced intercross line; HS: Heterogeneous Stock; RIL: Recombinant Inbred Lines; MAGIC: Multi-parent Advanced Generation Inter-Cross; RPT: Recombinant Progeny Testing; ISCS: Interval-Specific Congenic Strains; g.d.p.: genotyping data points; SEQTN: Standard error of QTN.

\section{Competing interests}

The authors declare that they have no competing interests.

\section{Authors' contributions}

MS conceived of the study, and participated in its design and implementation and helped to draft the manuscript. EMH wrote and ran the simulation, verified the analyses and participated actively in all stages of manuscript preparation. Both authors read and approved the final manuscript.

\section{Acknowledgements}

Except for EH and MS, no one else made a substantial contribution to the conception, design, acquisition of data, or analysis or was involved in drafting the manuscript or revising it critically for important intellectual content. Preparation of the manuscript was self-funded and did not include a language editor or scientific writer. The present study itself was self-funded and was not supported by a grant from a funding agency. Publication page costs were provided by the Research Authority of JCT - Lev Academic Center.

\section{Author details}

${ }^{1}$ JCT - Lev Academic Center, 21 Havaad Haleumi, Jerusalem, Israel. ${ }^{2}$ Department of Genetics, Silverman Life Sciences Institute, Edmund Safra Campus, The Hebrew University of Jerusalem, 91904 Jerusalem, Israel.

Received: 23 September 2014 Accepted: 22 April 2015 Published online: 07 July 2015

\section{References}

1. Carlson CS, Eberle MA, Kruglyak L, Nickerson DA. Mapping complex disease loci in whole-genome association studies. Nature. 2004;429:446-52.

2. Darvasi A. Experimental strategies for the genetic dissection of complex traits in animal models. Nat Genet. 1998;18:19-24.

3. Darvasi A, Soller M. Advanced intercross lines, an experimental population for fine genetic mapping. Genetics. 1995;141:1199-207.

4. Iraqi F, Clapcot S, Kuman P, Heley C, Kemp S, Teale A. Fine mapping of trypanosomiasis resistance QTLs in mice using advanced intercross lines. Mamm Genome. 2000;11:645-8.

5. Mott R, Talbot CJ, Turri MG, Collins AC, Flint J. A method for fine mapping quantitative trait loci in outbred animal stocks. PNAS. 2000;97:12649-54.

6. Svenson KL, Gatti DM, Valdar W, Welsh CE, Cheng R, Chesler EJ, et al. High-resolution genetic mapping using the mouse diversity outbred population. Genetics. 2012;190:437-47.

7. Darvasi A. Dissecting complex traits: the geneticists 'Around the world in 80 days'. Trends Genet. 2005:21:373-6.

8. Yalcin B, Willis-Owen SAG, Fullerton J, Meesaq A, Deacon RM, Rawlins JNP et al. Genetic dissection of a behavioral quantitative trait locus shows that Rgs2 modulates anxiety in mice. Nat Genet. 2004;36:1197-202.

9. Falke KC, Frisch M. Power and false positive rate in QTL detection with near-isogenic line libraries. Heredity. 2011;106:576-84.

10. Paterson AH, DeVerna JW, Lanini B, Tanksley SD. Fine mapping of quantitative trait loci using selected overlapping recombinant chromosomes in an interspecific cross of tomato. Genetics. 1990;124:735-42.

11. Eshed Y, Zamir D. An introgression line population of Lycopersicon penelli in the cultivated tomato enables the identification and fine mapping of yield associated QTL. Genetics. 1995;141:1147-62.

12. Churchill GA, Airey DC, Allayee H, Angel JM, Attie AD, Beatty J, et al. Complex trait consortium (2004). the collaborative cross, a community resource for the genetic analysis of complex traits. Nat Genet. 2004;36:1133-7.

13. Iraqi FA, Athamni $H$, Dorman A, Salymah $Y$, Tomlinson I, Nashif A, et al. Heritability and coefficient of genetic variation analyses of phenotypic traits provide strong basis for high-resolution QTL mapping in the Collaborative Cross mouse genetic reference population. Mamm Genome. 2014;25:109-19.

14. Cavanagh C, Morell M, Mackay I, Powell W. From mutations to MAGIC: resources for gene discovery, validation and delivery in crop plants. Curr Opin Plant Biol. 2008;11:215-21.

15. Kover PX, Valdar W, Trakalo J, Scarcelli N, Ehrenreich IM, Purugganan MD, et al. A multiparent advanced GenerationInter-cross to fine-map quantitative traits in Arabidopsis thaliana. PLoS Genet. 2009;5:e1000551.

16. Huang BE, George AW, Forrest KL, Kilian A, Hayden MJ, Morell MK, et al. A multiparent advanced generation inter-cross population for genetic analysis in wheat. Plant Biotechnol J. 2012;10:826-39. 
17. Bandillo N, Raghavan C, Muyco PA, Sevilla MAL, Lobina IT, Dilla-Ermita CJ, et al. Multi-parent advanced generation inter-cross (MAGIC) populations in rice: progress and potential for genetics research and breeding. Rice. 2013;6:11.

18. Rosa GJM, Leon ND, Rosa AJM. Review of microarray experimental design strategies for genetical genomics studies. Physiol Genomics. 2006;28:15-23.

19. Jin C, Lan H, Attie AD, Churchill GA, Bulutuglo D, Yandell S. Selective phenotyping for increased efficiency in genetic mapping studies. Genetics. 2004; 168:2285-93.

20. Xu Z, Zou F, Vision TJ. Improving quantitative trait loci mapping resolution in experimental crosses by the Use of genotypically selected samples. Genetics. 2005;170:401-8.

21. Spickett SP, Thoday JM. Regular responses to selection; 3. Interaction between located polygenes. Genet Res. 1966;7:96-121.

22. Liu X, Oliver F, Brown SDM, Denny P, Keightley PD. High-resolution quantitative trait locus mapping for body weight in mice by recombinant progeny testing. Genet Res. 2001;77:191-7.

23. Darvasi A. Interval-specific congenic strains (ISCS): an experimental design for mapping a QTL into a 1-centimorgan interval. Mamm Genome. 1997;8:163-7.

24. Wang $L$, Jiao $Y$, Huang $Y$, Bennett $B$, Williams RW, Li D, et al. Ttn as a likely causal gene for QTL of alcohol preference on mouse chromosome 2. BMC Bioinformatics. 2014;15 Suppl 10:12.

25. Ronin Y, Korol A, Shtemberg M, Nevo E, Soller M. High-resolution mapping of quantitative trait loci by selective recombinant genotyping. Genetics. 2003;164:1657-66.

26. Weller Jl, Soller M. An analytical formula to estimate confidence interval of QTL location with a saturated genetic map as a function of experimental design. Theor Appl Genet. 2004;109:1224-9.

27. Darvasi A, Soller M. Selective genotyping for determination of linkage between a marker locus and a quantitative trait locus. Theor Appl Genet. 1992:85:353-9.

28. Darvasi A, Soller M. Selective DNA pooling for determination of linkage between a molecular marker and a quantitative trait locus. Genetics. 1994;138:1365-73.

29. Lipkin E, Mosig MO, Darvasi A, Ezra E, Shalom A, Friedmann A, et al. Mapping loci controlling milk protein percentage in dairy cattle by means of selective milk DNA pooling using dinucleotide microsatellite markers. Genetics. 1998;149:1557-67.

30. Mather K, Jinks JL. Biometrical Genetics. London: Chapmand and Hall; 1970

\section{Submit your next manuscript to BioMed Central and take full advantage of:}

- Convenient online submission

- Thorough peer review

- No space constraints or color figure charges

- Immediate publication on acceptance

- Inclusion in PubMed, CAS, Scopus and Google Scholar

- Research which is freely available for redistribution 